\title{
Corrosion behaviour of laser-cleaned AA7024 aluminium alloy
}

DOI:

10.1016/j.apsusc.2017.11.141

\section{Document Version}

Accepted author manuscript

Link to publication record in Manchester Research Explorer

\section{Citation for published version (APA):}

Zhang, F. D., Liu, H., Subka, C., Liu, Y., Liu, Z., Guo, W., Cheng, Y. M., Zhong, S., \& Li, L. (2018). Corrosion behaviour of laser-cleaned AA7024 aluminium alloy. Applied Surface Science, 435, 452-461.

https://doi.org/10.1016/j.apsusc.2017.11.141

\section{Published in:}

Applied Surface Science

\section{Citing this paper}

Please note that where the full-text provided on Manchester Research Explorer is the Author Accepted Manuscript or Proof version this may differ from the final Published version. If citing, it is advised that you check and use the publisher's definitive version.

\section{General rights}

Copyright and moral rights for the publications made accessible in the Research Explorer are retained by the authors and/or other copyright owners and it is a condition of accessing publications that users recognise and abide by the legal requirements associated with these rights.

\section{Takedown policy}

If you believe that this document breaches copyright please refer to the University of Manchester's Takedown Procedures [http://man.ac.uk/04Y6Bo] or contact uml.scholarlycommunications@manchester.ac.uk providing relevant details, so we can investigate your claim.

\section{OPEN ACCESS}




\section{Corrosion behaviour of laser-cleaned AA7024 aluminium alloy}

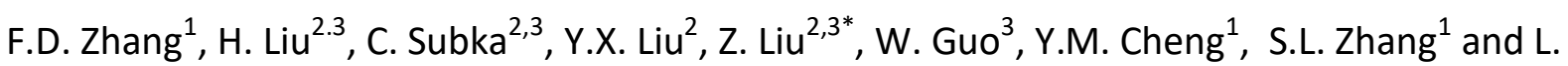
$\mathrm{Li}^{3}$,

${ }^{1}$ CRRC Qingdao Sifang Rolling Stock Co. Ltd., Qingdao, Shandong, P.R. China, 266111

${ }^{2}$ School of Materials, The University of Manchester, Manchester M13 9PL, UK

${ }^{3}$ Laser Processing Research Centre, School of Mechanical and Civic Engineering, The University of Manchester, Manchester M13 9PL, UK

*Corresponding author:

Dr Zhu Liu

Tel: 00441613064845

Email: zhu.liu@manchester.ac.uk 


\begin{abstract}
Laser cleaning has been considered as a promising technique for the preparation of aluminium alloy surfaces prior to joining and welding and has been practically used in the automotive industry. The process is based on laser ablation to remove surface contaminations and aluminium oxides. However the change of surface chemistry and oxide status may affect corrosion behaviour of aluminium alloys. Until now, no work has been reported on the corrosion characteristics of laser cleaned metallic surfaces. In this study, we investigated the corrosion behaviour of laser-cleaned AA7024-T4 aluminium alloy using potentiodynamic polarisation, electrochemical impedance spectroscopy (EIS) and scanning vibrating electrode technique (SVET). The results showed that the laser-cleaned surface exhibited higher corrosion resistance in $3.5 \mathrm{wt} . \% \mathrm{NaCl}$ solution than as-received hot-rolled alloy, with significant increase in impedance and decrease in capacitance, while SVET revealed that the active anodic points appeared on the as-received surface were not presented on the laser-cleaned surfaces. Such corrosion behaviours were correlated to the change of surface oxide status measured by glow discharge optical emission spectrometry (GDOES) and X-ray photoelectron spectroscopy (XPS). It was suggested that the removal of the original less protective oxide layer consisting of $\mathrm{MgO}$ and $\mathrm{MgAl}_{2} \mathrm{O}_{4}$ on the as-received surfaces and the newly formed more protective oxide layer containing mainly $\mathrm{Al}_{2} \mathrm{O}_{3}$ and MgO by laser cleaning were responsible for the improvement of the corrosion performance.
\end{abstract}

Keywords: laser cleaning; aluminium alloy; corrosion; SVET; EIS; polarisation; XPS; GDOES. 


\section{Introduction}

Laser cleaning has been considered as an alternative method to replace conventional cleaning techniques such as wet chemicals and mechanical cleaning involving air abrasives or grinding. Compared with the conventional cleaning techniques, laser cleaning offers advantages including environment-friendliness, better selectivity, better controllability, better flexibility to achieve complete removal of surface contamination with minimal damage to the underlying substrate material and the process can be much faster for welding surface preparations since only localised cleaning is required.

Laser cleaning is a versatile process that can be applied to many different kinds of contaminates and substrates. For example, the removal of adherent particles from semiconductors [1], aerospace mould cleaning [2] and paint stripping [3] have been widely reported. In recent years, laser cleaning has been considered as a pre-treatment technique for coating, welding and joining of various materials, and also a post-treatment technique to remove stains and discoloration after welding [4-7]. These processes involve the removal of contaminates such as oil and grease, or the removal of metal oxides from metallic substrates. Removal of organic contaminants is based on laser beam disintegration or vaporisation of contaminants, so that no significant thermal effect on the substrate is expected. However, to remove an oxide layer, the interaction between the laser beam and oxide layer may generate sufficient thermal effects to induce additional thermal oxidation or even melting a thin layer of the surface. Such a thermal effect is dependent on several factors, including laser beam wavelength, pulse width, laser processing parameters, thickness of oxide layers, nature of oxide layers as well as substrate materials. It was known that three mechanisms in laser removal of oxide layers from metallic substrates exist, i.e. 
thermal ablation, mechanical effect, and combined thermal ablation and mechanical effects. It was reported by Kearns et al [8] that the mechanism in the removal of copper oxide of a thickness of $300 \mathrm{~nm}$ from a copper substrate by lasers at wavelengths of $1064 \mathrm{~nm}, 532 \mathrm{~nm}$ and $266 \mathrm{~nm}$, with nanosecond pulses was combined thermal and mechanical effects. The laser cleaning with a wavelength of $532 \mathrm{~nm}$ further induced thermal oxidation turning the original $\mathrm{CuO}_{2}$ to black $\mathrm{CuO}$. When a ns Nd:YAG laser with a relatively low fluence was applied on a high-temperature oxidised stainless steel, the removal of the oxide layer of $1 \mu \mathrm{m}$ in thickness was mechanical in nature, with no occurrence of thermal ablation [9]. Another investigation was reported by Dimogerontakis, et. al [10] that when a Nd:YAG laser with a $1064 \mathrm{~nm}$ wavelength and a $10 \mathrm{~ns}$ pulse width was applied to removing lubricants and native oxide layers from an Al-Mg alloy, it was found that thermal oxidation took place on the AlMg alloy during the laser irradiation in air with a laser fluence ranged from 0.6 to $1.4 \mathrm{~J} / \mathrm{cm}^{2}$. It was demonstrated that the thermal oxidation had the same mechanism as in the case of the steady state thermal oxidation of the Al-Mg alloys even though the laser irradiation was only for a short period of $10 \mathrm{~ns}$. Increasing the laser fluence increased the thickness of oxide layers. When the laser fluence was increased to $1 \mathrm{~J} / \mathrm{cm}^{2}$, the oxide layer formed by the thermal oxidation became, in a large extent, crystalline and its outer part was entirely covered by a continuous layer of magnesium oxide.

Therefore, it is believed that laser cleaning in air, particularly for reactive metallic substrates such as aluminium alloys and titanium alloys, to remove oxide layers could induce further thermal oxidation and form new oxide layers on the surface. Such newly formed oxide layers may have different oxide constituents that would be likely to affect its corrosion behaviour. However, up to date, no work has been reported on the corrosion characteristics 
of laser cleaned mechanic materials. In this work, we investigated the corrosion behaviour of laser-cleaned AA7024-T4 alloy using an Nd:YAG laser with a wavelength of $1064 \mathrm{~nm}$ and a pulse width of $10 \mathrm{~ns}$. Surface analysis of the laser-cleaned surface was carried out using XPS and GDOES, and compared with the as-received hot-rolled alloy. The correlation between the corrosion behaviour and the change of surface oxides before and after the laser cleaning was established.

\section{Experimental procedure}

\subsection{Material and laser processing procedure}

AA7024-T4 hot-rolled plates of $8 \mathrm{~mm}$ thickness were used as-received condition. The chemical composition of AA7024-T4, wt.\% was determined by EDX as Al-5.8Zn-1.5Mg1.1Cr-0.3Fe-0.2Cu-0.7Mn-0.3 Si.

Laser cleaning was carried out using a ALT-LC-NP-500 Diode pumped nanosecond pulsed Fibre laser (Advanced Laser Technology Ltd.) with a wavelength of $1064 \mathrm{~nm}$, a pulse width of $10 \mathrm{~ns}$ and a repetition rate of $10 \mathrm{kHz}$ in ambient atmosphere. Laser fluences were varied in the range of $3.5 \mathrm{~J} / \mathrm{cm}^{2}, 5.7 \mathrm{~J} / \mathrm{cm}^{2}, 7.1 \mathrm{~J} / \mathrm{cm}^{2} 8.5 \mathrm{~J} / \mathrm{cm}^{2}$ and $11.3 \mathrm{~J} / \mathrm{cm}^{2}$. The beam spot size on the target surface was $0.6 \mathrm{~mm}$; the scanning velocity was $600 \mathrm{~mm} / \mathrm{s}$, and the number of pules per unit area was fixed at 10 .

\subsection{Surface analyses}

Surface morphology and cross section of AA7024-T4 alloy before and after laser cleaning was examined by a Zeiss Sigma VP FE-SEM (field emission scanning electron microscope. The elemental mapping of the upmost layers particularly the oxide layers was obtained using 
attached Energy Dispersive Spectroscopy (EDS). The surface profiles with roughness measurement were obtained using a Bruker's ContourGT-X white light interferometry.

Elemental depth profiles were measured by glow discharge optical emission spectroscopy (GDOES) using a Horiba-Jobin-Yvon GD Profiler 2 in an argon atmosphere of $635 \mathrm{~Pa}$ by applying rf of $13.56 \mathrm{MHz}$ and power of $35 \mathrm{~W}$ with a sampling time of $0.01 \mathrm{~s}$. The measured area was $4 \mathrm{~mm}$ in diameter. The wavelengths in $\mathrm{nm}$ of the spectral lines employed for the detection of relevant elemental species were as follows: Al, 396.157; $\mathrm{Mg}, 383.834$; Fe, 371.99; Cr, 425.439; Si, 288.162; Zn, 481.060, Mn, 403.455; $\mathrm{Cu}, 324.759 ; \quad \mathrm{C}, 156.149 ; \mathrm{O}$, $130.223 ; \mathrm{N}, 149.267$; and $\mathrm{H}, 121.574$. Surface chemistry and oxide states of the alloy before and after the laser cleaning was also measured using X-ray photoelectron spectroscopy (XPS, Kratos Ultra).

\subsection{Corrosion testing}

Potentiodynamic polarization and Electrical Impedance Spectroscopy (EIS) tests were performed in 3.5 wt.\% $\mathrm{NaCl}$ solution at room temperature using a Princeton Applied Research (PAR) potentiostat, with an electrochemical cell consisting of three electrodes, i.e. platinum mesh as counter electrode, saturated calomel electrode (SCE) as the reference electrode. The samples with an exposed area of $1.0 \mathrm{~cm}^{2}$ as the working electrode were used. The EIS data were fitted using a commercial software Z-view.

SVET (Scanning Vibrating Electrode Technique) measurements were carried out using a custom designed SVET system. The micro-electrode had a spherical black platinum tip of 10 $\mu \mathrm{m}$ in diameter. The probe was located $100 \mu \mathrm{m}$ above the surface and vibrated in the perpendicular direction to the surface $(Z)$ with amplitude of $30 \mu \mathrm{m}$. The vibration frequency 
of the probe was $140 \mathrm{~Hz}$. A calibration routine converted the measured potentials into current density at the corroding surface. Experimental results are presented in the form of 2D maps of ionic currents using the data from the electric field normal to the surface. Positive (red color in 2D map) values correspond to the anodic activity and negative values (blue color in 2D map) to the cathodic activity. The electrolyte used for SVET was 3.5 wt.\% $\mathrm{NaCl}$ solution. The scanned area was approximately $1 \mathrm{~cm}^{2}$. All the experiments were carried out under ambient condition of $20 \pm 1^{\circ} \mathrm{C}$. For the purpose of comparison, ground surfaces were also prepared by manually grinding using 800 grit and followed by 1200 grit sandpaper to remove the dark appearance of the alloy prior to the corrosion tests described above.

\section{Results and Discussion}

\subsection{Surface observation and compositional analysis}

The surface of the as-received AA7024-T4 alloy was dark to naked eyes, implying the presence of a relatively thick oxide layer, but it became brighter after laser cleaning with increasing laser fluences. Fig. 1 is the UV-vis spectra of the alloy surfaces before and after laser cleaning. It shows that both the laser-cleaned surfaces at $7.1 \mathrm{~J} / \mathrm{cm}^{2}$ and $8.5 \mathrm{~J} / \mathrm{cm}^{2}$ laser flunces showed similar highest reflectance exhibiting the brightest surfaces, and then the reflectance decreased but was still greater than the as-received surface. Fig. 2 shows the surface morphologies of the AA7024 alloy before and after laser cleaning. The as-received surface exhibited various contaminate, and scratches, while all the laser-cleaned surfaces were almost contaminant-free. When the laser fluence was $7.1 \mathrm{~J} / \mathrm{cm}^{2}$, the cleaned surface was bright as described earlier, but the surface was partially melted. Further increasing in the laser fluence up to $11.3 \mathrm{~J} / \mathrm{cm}^{2}$ led to fully melted surfaces with a typical wavy solidification structure. The surface profiles, as shown in Fig. 3 showed that the laser 
cleaning resulted in an increase of surface roughness compared with Ra value of $305 \mathrm{~nm}$ for the as-received, and the roughness increased from $375 \mathrm{~nm}$ to $1691 \mathrm{~nm}$ with increasing laser fluences. The surface profiles in Fig. 3 also provided an evidence of changing surface morphologies with increasing laser fluence. It was worth stating here that the increase in the surface reflectance after laser cleaning was mainly attributed to the removal of the oxide layer that was dark in appearance s well as other contaminants. Therefore, the lasercleaned surface with increased surface roughness still presented higher reflectance.

Cross sectional observation by SEM along with EDS mapping shown in Fig. 4 indicates that the as-received surface presented an oxygen rich region with a depth of approximately 800 $\mathrm{nm}$. Within this region, magnesium was also rich, which was believed to be the result of faster diffusion of $\mathrm{Mg}$ towards the surface than the other elements during the hot-rolling process. From the SEM image, this oxygen-rich region contained two distinctive layers. The upper layer was porous and magnesium rich, while the lower part was less porous with even higher magnesium content with a strong adhesion to the alloy substrate. It was likely that the oxygen-rich region was composed of oxides and maybe other compounds. However, it was likely that the magnesium-rich layer was also presented in the aluminium solid solution just underneath the oxygen-rich layer. The laser-cleaned surface at $7.1 \mathrm{~J} / \mathrm{cm}^{2}$ showed that the thickness of the oxygen-rich region was less than $100 \mathrm{~nm}$, and still contained magnesium although the magnesium content was much reduced. From the SEM image, it seemed that the upper layer was completely removed, but it was difficult to determine if the lower layer was also removed or partially removed. To answer the question, the elemental depth profiles and surface chemistry of the surface before and after laser cleaning were measured 
by GDOES and XPS. In addition, the EIS data could also provide information related to the thickness of each individual layer.

Figure 5 shows the elemental depth profiles obtained by GDOES for the as-received and laser-cleaned surface at $7.1 \mathrm{~J} / \mathrm{cm}^{2}$. The depth profile of the as-received surface presented an intense peak of carbon, as well as the peak of hydrogen at the commencement of sputtering, which may be originated mostly from the oil and grease adsorbed on the as received surface. The intensities of these elemental peaks were reduced significantly after laser cleaning, suggesting that the laser cleaning process sufficiently removed these organic contaminants. However, the hydrogen was also likely to be co-existent in the oxide layer as hydrogen has a higher solubility in aluminium oxide than in aluminium matrix. The removal of hydrogen in the oxide layer also occurred accompanying the removal of the oxide layer. Another important observation was that the as-received surface showed an intense peak at the beginning of the sputtering which was located at the same position as the oxide layer on the sputtering time axis, implying that the magnesium was present in the oxide layer; in addition, a second peak of magnesium was also observed, which may represent the magnesium enrichment in the aluminium solid solution just below the oxide layer. This was consistent with the observation on the elemental mapping shown in Fig. 4 b. The intensities of oxygen and magnesium peaks after laser cleaning were significantly reduced, providing a further evidence of removal of the oxide layer. In addition, the zinc profile showed depletion on the top surface, but became relatively uniform distributing along the depth after laser cleaning. Finally it was worth mentioning that the intensity of hydrogen, appeared mostly within the upper layer, was reduced after laser cleaning. This is important when laser cleaning of aluminium alloys is applied. 
XPS wide scan spectra of the as-received AA7024-T4 alloy, as well as high resolution scans of $\mathrm{Mg} 2 \mathrm{~s}, \mathrm{C}$ 1s and $\mathrm{O}$ 1s are shown in Fig. 6 . The alloy containing aluminium and magnesium could present a number of spectral possibilities. For example, the Al $2 p$ peak can be overlapped by Mg Ka X-ray satellites, and the Mg $2 p$ peak can be overlapped by a C 1s X-ray ghost line caused by the stray $\mathrm{Al} \mathrm{K} \alpha \mathrm{X}$-ray radiation when using a dual $\mathrm{Mg} / \mathrm{Al} \mathrm{X}$-ray source [11]. Therefore, in this study, the quantitative analysis of magnesium and aluminium was done using $\mathrm{Mg} 2 \mathrm{~s}$ and $\mathrm{Al} 2 \mathrm{~s}$, which are free from artefacts.

The $\mathrm{MgAl}_{2} \mathrm{O}_{4}$ compound was identified, as all the spectral feature peaks of $\mathrm{Mg} 2 \mathrm{~s}, \mathrm{Al} 2 \mathrm{~s}$ and $\mathrm{O}$ 1s were present. The concentrations of $\mathrm{Mg}, \mathrm{Al}$ and $\mathrm{O}$ in at. $\%$ were $57.85 \%, 36.66 \%$ and 5.49\% respectively. As $\mathrm{MgAl}_{2} \mathrm{O}_{4}$ presents the atomic ratio of $\mathrm{Mg}: \mathrm{Al}: \mathrm{O}$ as 1:2:4, it was most likely that all the aluminium attributed to the formation of $\mathrm{MgAl}_{2} \mathrm{O}_{4}$, and the excessive amount of magnesium and oxygen may be combined to form other compounds. The fitting of the high resolution spectra of $\mathrm{Mg} 1 \mathrm{~s}$ and $\mathrm{C} 1 \mathrm{~s}$ confirmed that the magnesium was in the form of pure $\mathrm{MgO}$, and other organic contaminants also presented. The high resolution XPS spectrum of $01 \mathrm{~s}$ further confirmed that the as-received AA7024 surface presented a mixture of three components of $\mathrm{MgO}(43.36 \%), \mathrm{MgAl}_{2} \mathrm{O}_{4}(11.05 \%)$ and organic species (45.59\%), as shown in Fig $6 \mathrm{~d}$. It was surprised that no $\mathrm{Al}_{2} \mathrm{O}_{3}$ was detected. This finding was in agreement with the work reported by Shimizu, et.al. [12], in which the oxide layer on a high-temperature oxidised $\mathrm{Al}-0.5 \mathrm{wt} . \% \mathrm{Mg}$ alloy at $723 \mathrm{~K}$ was comprised of $\mathrm{MgO}$ and $\mathrm{MgAl}_{2} \mathrm{O}_{4}$. As described earlier, the as-received surface presented a two-layer structure of the oxygen-rich region. Therefore, it was believed that the upper part consisted of $\mathrm{MgO}$ and $\mathrm{MgAl}_{2} \mathrm{O}_{4}$. However, it was not possible to determine the constitutes of the lower part from the current research. 
A similar quantitative analysis of the laser-cleaned sample at $7.1 \mathrm{~J} / \mathrm{cm}^{2}$ fluence as shown in Fig. 7 indicates that the surface consisted of $\mathrm{MgO}$ and $\mathrm{Al}_{2} \mathrm{O}_{3}$ components with $81.53 \%$ and organic compounds with $18.47 \%$, while no $\mathrm{MgAl}_{2} \mathrm{O}_{4}$ was detected. It suggested that the laser cleaning at $7.1 \mathrm{~J} / \mathrm{cm}^{2}$ laser fluence sufficiently reduced the amount of the organic contaminants, and completely removed the upper layer containing $\mathrm{MgO}$ and $\mathrm{MgAl}_{2} \mathrm{O}_{4}$. The presence of $\mathrm{Al}_{2} \mathrm{O}_{3}$ should be a newly formed oxide due to the thermal effect induced by the laser cleaning, rather than decomposition of $\mathrm{MgAl}_{2} \mathrm{O}_{4}$.

\subsection{Corrosion behaviour}

The potentiodynamic polarisation curves for the as-received, mechanically ground and lasercleaned at $7.1 \mathrm{~J} / \mathrm{cm}^{2}$ and $11.3 \mathrm{~J} / \mathrm{cm}^{2}$ are presented in Fig. 8. All the surfaces had close values of free corrosion potentials. No passive plateau was observed in the anodic parts of the polarisation curves, suggesting that the anodic activities always dominated when applied anodic potentials. Significant differences were observed in the cathodic part of the polarisation curves; the laser-cleaned surfaces presented lower corrosion current densities than the as-received and mechanically ground, indicating that the laser cleaning decreased the cathodic activities of the alloy when applied cathodic potentials.

Figure 9 shows the EIS raw dotted lines, fitting lines and the equivalent circuit used for the as-received, mechanically ground and laser-cleaned at $7.1 \mathrm{~J} / \mathrm{cm}^{2}$ and $11.3 \mathrm{~J} / \mathrm{cm}^{2}$. The fitting results of electric components were summarized in Table 1 . The circuit in Fig. 9(e) comprised 3 resistors, 2 capacitors and a Warburg component. The constant phase elements (CPEs) for the representation of the capacitances of different layers were applied, and the calculation of the capacitances of layers was made using a Brug's equation [13], modified by the authors: 
$C_{i}=Q_{i}^{\frac{1}{n_{i}}} \cdot\left(\frac{1}{R_{S}}+\frac{1}{R_{i}}\right)^{\frac{n_{i}-1}{n_{i}}}$

Where $Q$ is the CPE value, $\Omega^{-1} \mathrm{~cm}^{-2}, n$ is the CPE dimensionless exponent and $R_{S}$ represents the solution resistance. The Warburg components existed only for the laser-cleaned surface at $11.3 \mathrm{~J} / \mathrm{cm}^{2}$ to evaluate the mass diffusion in the proximate of the alloy surface. $R_{W_{s}}$ is accounted for the diffusion resistance, $W_{S^{-}} T$ for the length of the diffusion layer and $W_{S^{-}} P$ for Warburg exponent [14].

For the as-received sample, a two-layer structure was identified. In the circuit, the outer layer corresponded to the upper layer of the oxygen-rich region, as described earlier, while the oxide corresponded to the lower part of the oxygen rich region. The resistance of the outer layer was $220.900 \Omega . \mathrm{cm}^{2}$ and it was lower than the resistance of the oxide layer of $2561.000 \Omega . \mathrm{cm}^{2}$. This suggested that the outer layer was less protective. Capacitance of the outer layer ( $C_{\text {outer layer }}$ ) was calculated using equation ( 1 ) and $R_{i}$ was substituted by $R_{\text {outer layer. }}$ Similarly, for the calculation of capacitance of the oxide $\left(C_{\text {oxide }}\right), R_{i}$ was replaced by $R_{\text {oxide. }}$. The

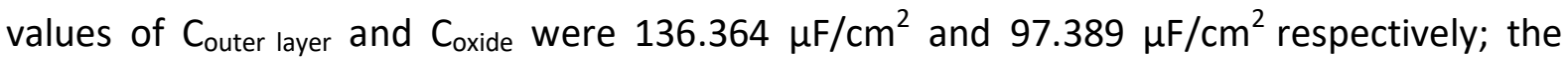
difference further confirmed that the outer layer was less protective.

After laser cleaning, only one oxide layer existed representing the newly formed oxide layer. The newly formed oxide layer exhibited a significant increase of resistances. At the laser fluence of $7.1 \mathrm{~J} / \mathrm{cm}^{2}$, the resistance was $70421 \Omega . \mathrm{cm}^{2}$ and at $11.3 \mathrm{~J} / \mathrm{cm}^{2}$, the resistance reached $182100 \Omega . \mathrm{cm}^{2}$. This indicates that the laser-induced oxide layer provided a considerably better protection to the alloy. Capacitance of this oxide layer at $7.1 \mathrm{~J} / \mathrm{cm}^{2}$ was obtained from equation (1) using $R_{\text {oxide }}$ to replace $R_{i}$, while at $11.3 \mathrm{~J} / \mathrm{cm}^{2}, R_{i}$ was replaced using the sum of $R_{\text {oxide }}$ and $R_{W_{s}}$ instead. The oxide capacitances for $7.1 \mathrm{~J} / \mathrm{cm}^{2}$ and $11.3 \mathrm{~J} / \mathrm{cm}^{2}$ 
were $3.364 \mu \mathrm{F} / \mathrm{cm}^{2}$ and $3.076 \mu \mathrm{F} / \mathrm{cm}^{2}$ respectively. Such small values suggested that the newly formed oxide layer after laser cleaning was thicker than the oxide layer on the asreceived samples. It was reasonable to believe that the oxide layer on the as-received alloy was not removed completely, and the laser-induced oxide layer consisting of $\mathrm{Al}_{2} \mathrm{O}_{3}$ and $\mathrm{MgO}$ was formed on top of it.

By comparison, the mechanical ground surface had an oxide-layer resistance of $4898 \Omega . \mathrm{cm}^{2}$ and an oxide-layer capacitance of $37.317 \mu \mathrm{F} / \mathrm{cm}^{2}$. The intermediate values of resistance and capacitance of the mechanically ground surface indicated that the outer layer and oxide layer on the as-received alloy were completely removed by grinding, followed by the formation of a thin, air-formed oxide layer. This air-formed layer was more protective than the layers on the as-received samples, but was not as much protective as the oxide layers after laser cleaning.

Figure 10 displays the SVET current density maps showing localised activities on the asreceived alloy surface with different immersion time. After 15 mins, two anodic current peaks appeared, representing the formation of pits. These pits did not seem to be stable. At the time of $4 \mathrm{~h}$ immersion, the small pit disappeared, and the big pit moved towards the left showing a strong anodic current density of $0.06 \mathrm{~A} / \mathrm{m}^{2}$; at the time of $12 \mathrm{~h}$ immersion, an anodic current peak appeared at the right side and then further increased its anodic activity with a current density up to $0.2 \mathrm{~A} / \mathrm{m}^{2}$, while no other anodic activities were detected. After the laser cleaning at $7.1 \mathrm{~J} / \mathrm{cm}^{2}$, the surface was dominated by cathodic areas after $4 \mathrm{hs}$ of immersion. One anodic peak appeared close to the edge on the upper side. However, this anodic area disappeared, and the whole surface was dominated by cathodic activity until the end of the test at 20 hs. 
The results from the polarisation, EIS and SVET had reached the same conclusion, i.e. the laser-cleaned surface presented a higher corrosion resistance than the as-received alloy. To explain the results, the change of surface chemistry and oxide status must be taken into account. As described earlier, the as-received surface presented a mixture of $\mathrm{MgO}$ and $\mathrm{MgAl}_{2} \mathrm{O}_{4}$, while the laser-cleaned surface at $7.1 \mathrm{~J} / \mathrm{cm}^{2}$ presented a mixture of $\mathrm{Al}_{2} \mathrm{O}_{3}$ and $\mathrm{MgO}$ with no presence of $\mathrm{MgAl}_{2} \mathrm{O}_{4}$. Although the mixture of $\mathrm{MgO}$ and $\mathrm{MgAl}_{2} \mathrm{O}_{4}$ provided a certain degree of protection against corrosion, the presence of $\mathrm{Al}_{2} \mathrm{O}_{3}$ was believed to be much more resistant to the corrosion in the presence of $\mathrm{Cl}^{-}$ions. The higher corrosion resistance for the laser-cleaned surface at $11.3 \mathrm{~J} / \mathrm{cm}^{2}$ than that at $7.1 \mathrm{~J} / \mathrm{cm}^{2}$ might be the result of thicker oxide layer formed and the excessive melting which might have modified the microstructure underneath the oxide layer, in terms of refinement of second phases. This is outside the scope of this paper, as an ideal laser cleaning is not supposed to cause such excessive melting of the substrate.

\section{Conclusions}

In this paper, the corrosion behavior of the hot-rolled AA7024-T4 alloy before and after laser cleaning was analyzed and compared with mechanical ground surfaces. Surface analyses and microstructural examinations were performed to provide the evidences on the removal of the original oxides, and the formation of a new oxide layer after laser cleaning, giving rise to improved corrosion resistance in an environment containing $\mathrm{Cl}^{-}$ions. The key findings are:

1) Laser cleaning at $7.1 \mathrm{~J} / \mathrm{cm}^{2}$ fluence with 10 pulses per location removed the original oxide layer comprising of $\mathrm{Mg}+\mathrm{MgAl}_{2} \mathrm{O}_{4}$, to form a new layer of $\mathrm{Al}_{2} \mathrm{O}_{3}+\mathrm{MgO}$.oxide film on the cleaned surface. 
2) The potentiodynamic polarization showed decreased corrosion current density after laser cleaning.

3) The EIS data showed that the laser-cleaned surface at $7.1 \mathrm{~J} / \mathrm{cm}^{2}$ dramatically increased impedance, indicating that the newly formed oxide layer by laser cleaning was more protective than the original oxide layer on the as-received surface.

4) The SVET current maps showed that the laser-cleaned at $7.1 \mathrm{~J} / \mathrm{cm}^{2}$ exhibited much less anodic activity while anodic current peaks presented on the as-received alloy surface was dramatic.

5) The improved corrosion resistance for the laser-cleaned surface was the result of removal of $\mathrm{MgO}+\mathrm{MgAl}_{2} \mathrm{O}_{4}$ which was less protective than the newly formed $\mathrm{Al}_{2} \mathrm{O}_{3}+\mathrm{MgO}$ layer.

6) Although the laser-cleaned surface at $11.3 \mathrm{~J} / \mathrm{cm}^{2}$ presented even better corrosion resistance, the surface was heavily melted. Such improvement might be caused by thicker oxide formation as well as the change of microstructures occurred in the aluminium matrix underneath the oxide layer.

7) The mechanically ground surface exhibited higher corrosion resistance than the asreceived, but lower than the laser-cleaned, due to the formation of air-formed oxide layer which was more protective than the $\mathrm{MgO}+\mathrm{MgAl}_{2} \mathrm{O}_{4}$ layer on the as-received surface, but less protective than the newly formed $\mathrm{Al}_{2} \mathrm{O}_{3}+\mathrm{MgO}$ layer by laser cleaning.

\section{Acknowledgement}

The authors acknowledge the funding of this research carried out at The University of Manchester, by CRRC Qingdao Sifang Rolling Stock Co. Ltd., agreement number: SF/JGliangsi-2016-211. 


\section{References:}

1. G. Vereecke, E. Rohr, M. M. Heyns, Laser-assisted removal of particles on silicon wafers, J. Appl. Phys. 85 (1999) 3837-3843.

2. R.E. Litchfield, G.W. Critchlow and S. Wilson, Surface cleaning technologies for the removal of crosslinked epoxide resin, International J. of Adhesion and Adhesives, 26 (2006) 295-303.

3. M.J.J. Schmidt, L. Li and J.T. Spencer, An investigation into the feasibility and characteristics of using a $2.5 \mathrm{~kW}$ high power diode laser for paint stripping, Journal of Materials Processing Technology, 138 (2003) 109-115.

4. A.W. Al-Shaer, L. Li and A. Mistry, The effects of short pulse laser surface cleaning on porosity formation and reduction in laser welding of aluminium alloy for automotive component manufacture, Optics \& Laser Technology, 64 (2014) 162-171.

5. Q. Wang, Y.C. Guan, B.Q. Cong and B.J. Qi, Laser cleaning of commercial Al alloy surface for tungsten inert gas welding", Journal of Laser Applications, 28 (2016) 022507.

6. T.L. See, Z. Liu, S. Cheetham, S. Dilworth and L. Li, Laser abrading of carbon fibre reinforced composite for improving paint adhesion, Applied Physics A - Materials Science \& Processing, 117 (2014) 1045-1054.

7. Jose Maria Sánchez-Amaya, Margarita Raquel Amaya Vázquez, Leandro González, Rovira, Javier Botana, Influence of Surface Pre-treatments on Laser Welding of Ti6Al4V Alloy, Journal of Materials Engineering and Performance, 23(2014) 15681575. 
8. A. Kearns, C. Fischer, K.G. Watkins, M. Glasmacher, H. Kheyrandish, A. Brown, W.M. Steen, O. Beahan, Laser removal of oxides from a copper substrate using Q-switched Nd:YAG radiation at $1064 \mathrm{~nm}, 532 \mathrm{~nm}$ and $266 \mathrm{~nm}$, Applied Surface Science, 127 (1998) 773-780.

9. P. Psyllaki and R. Oltra, Preliminary study on the laser cleaning of stainless steels after high temperature oxidation, Materials Science and Engineering A282 (2000) 145-152.

10. T. Dimogerontakis, R. Oltra and O. Heintz, Thermal oxidation induced during laser cleaning of an aluminium-magnesium alloy, Appl. Phys. A, 81 (2005) 1173.

11. B.R. Strohmeier, Magnesium Aluminate $\left(\mathrm{MgAl}_{2} \mathrm{O}_{4}\right)$ by XPS, Surface Science Spectra, 3 (1994) 121.

12. K. Shimizu, G.M. Brown, K. Kobayashi, P. Skeldon, G.E. Thompson and G.C. Wood, The early stages of high temperature oxidation of an Al-0.5wt\% Mg alloy, Corrosion Science, 40 (1998) 557-575.

13. G.J. Brug, A.L.G. Vandeneeden, M. Sluytersrehbach and J.H. Sluyters, The analysis of electrode impedances complicated by the presence of a constant phase element, J. Electroanal Chem, 176 (1984) 275-295.

14. J. Bisquert, G. Garcia-Belmonte, P. Bueno, E. Longo, L.O.S. Bulhoes, Impedance of constant phase element (CPE)-blocked diffusion in film Electrodes, J. Electroanal Chem, 452 (1998) 229-234. 


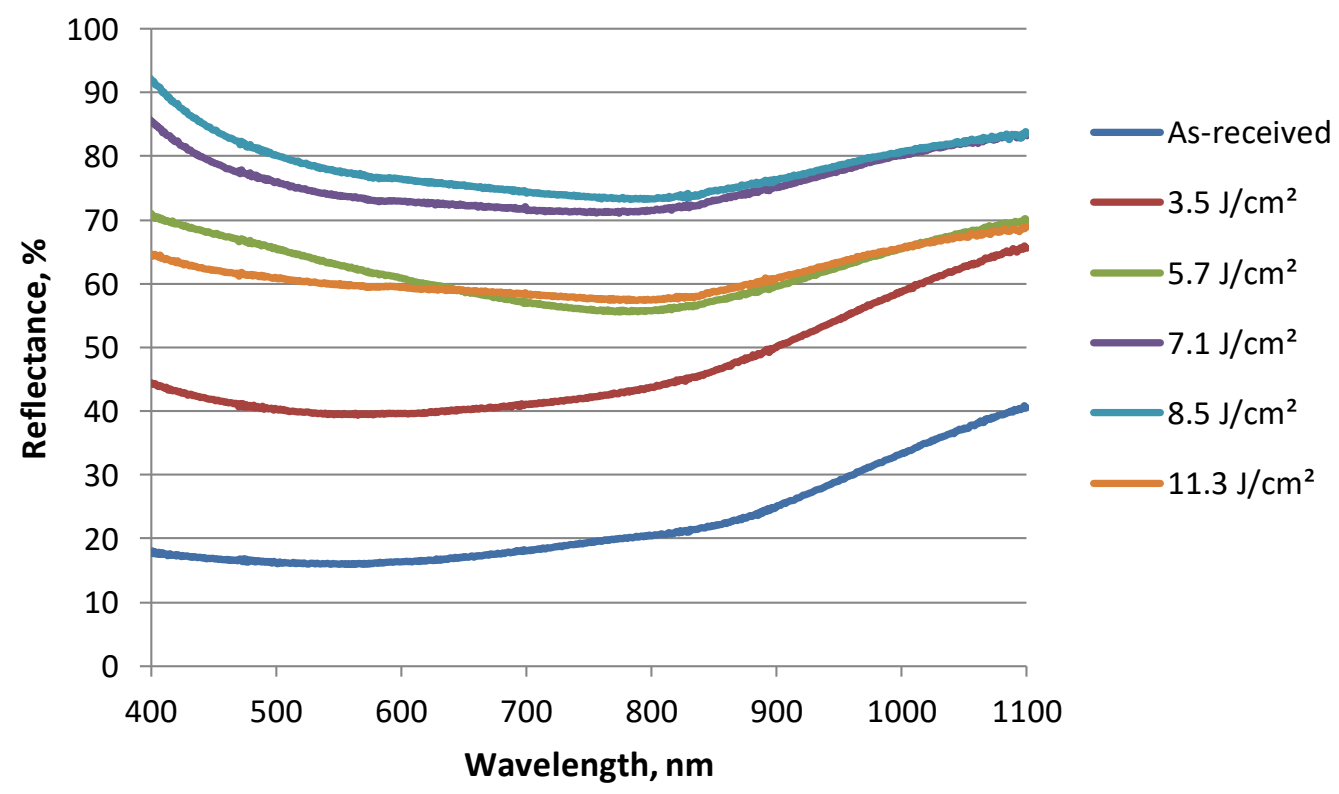

Figure 1: UV-vis spectra of the as-received and laser-cleaned alloy at different laser fluence. 


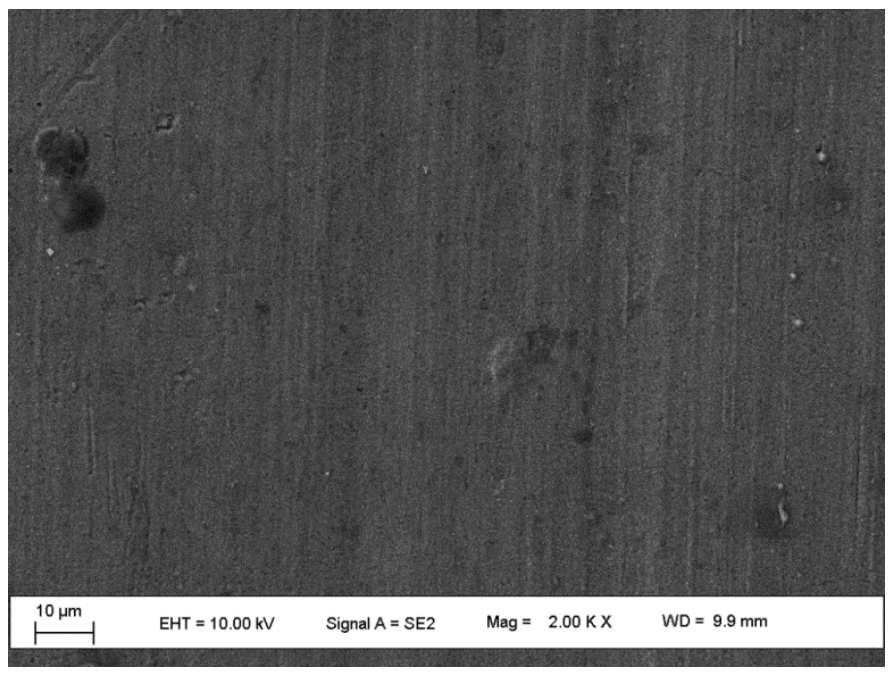

(a)

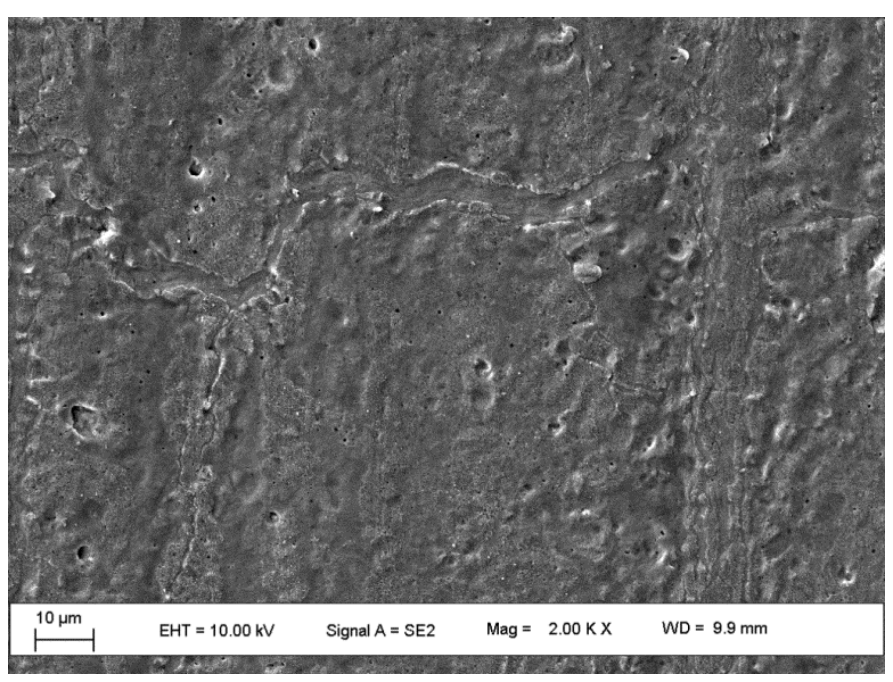

(b) 


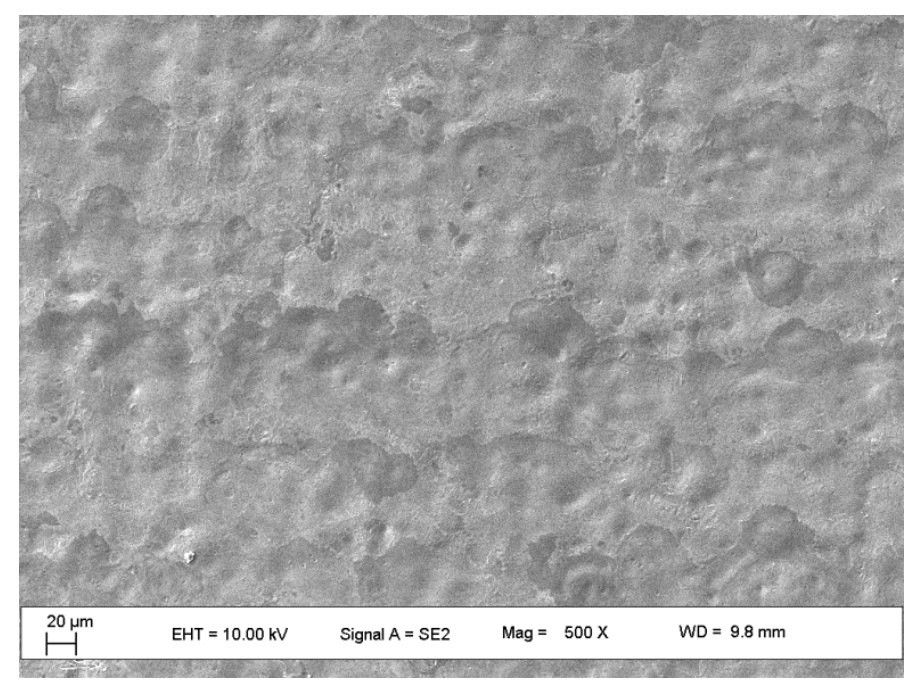

(c)

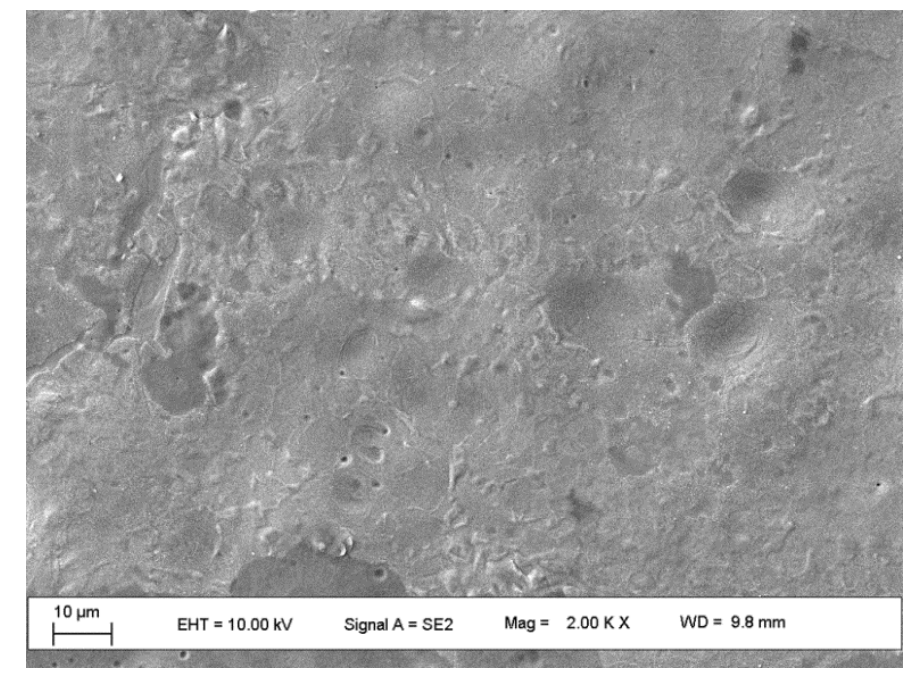

(d) 


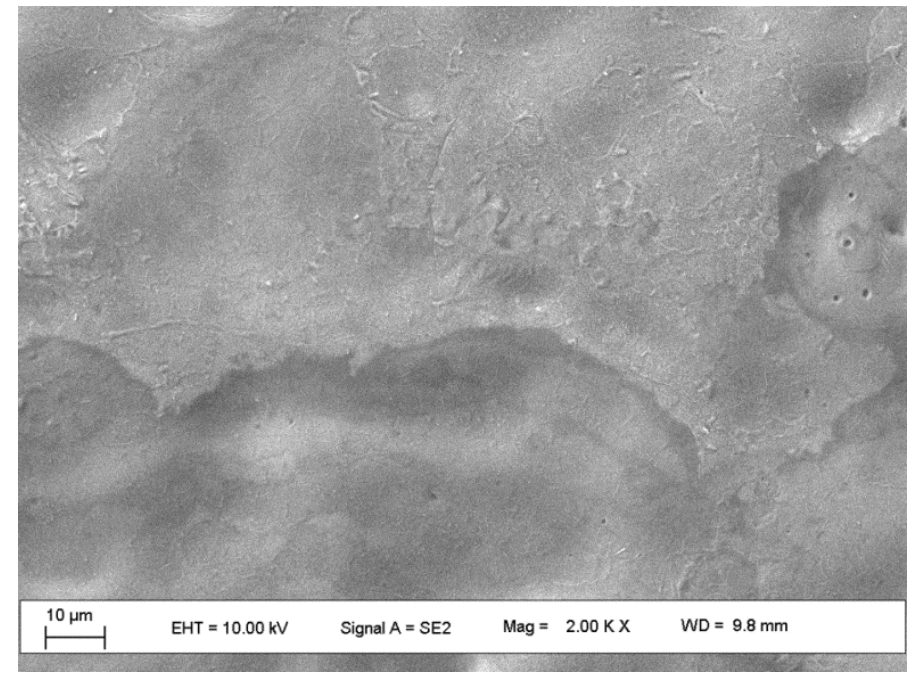

(e)

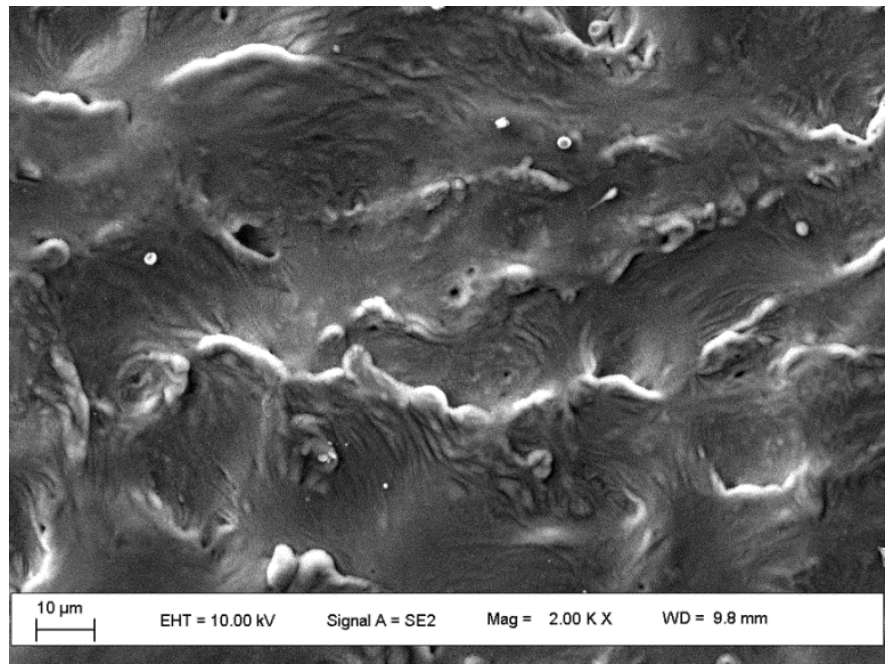

(f)

Figure 2: SEM surface morphologies of the alloy, (a) the as-received and laser-cleaned at (b) $3.5 \mathrm{~J} / \mathrm{cm}^{2}$, (c) $5.7 \mathrm{~J} / \mathrm{cm}^{2}$, (d) $7.1 \mathrm{~J} / \mathrm{cm}^{2}$, (e) $8.5 \mathrm{~J} / \mathrm{cm}^{2}$ and (f) $11.3 \mathrm{~J} / \mathrm{cm}^{2}$. 


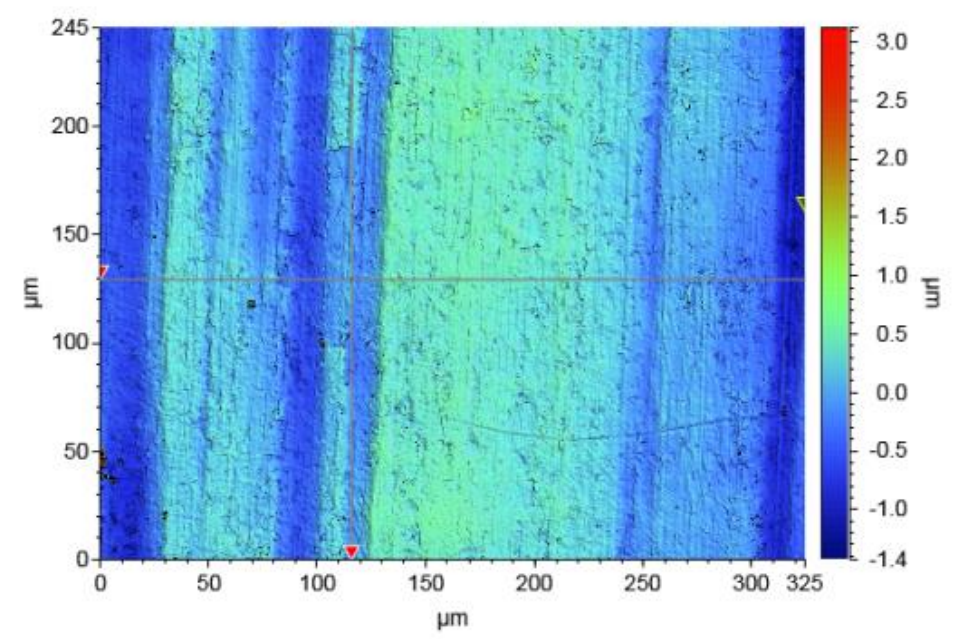

(a)

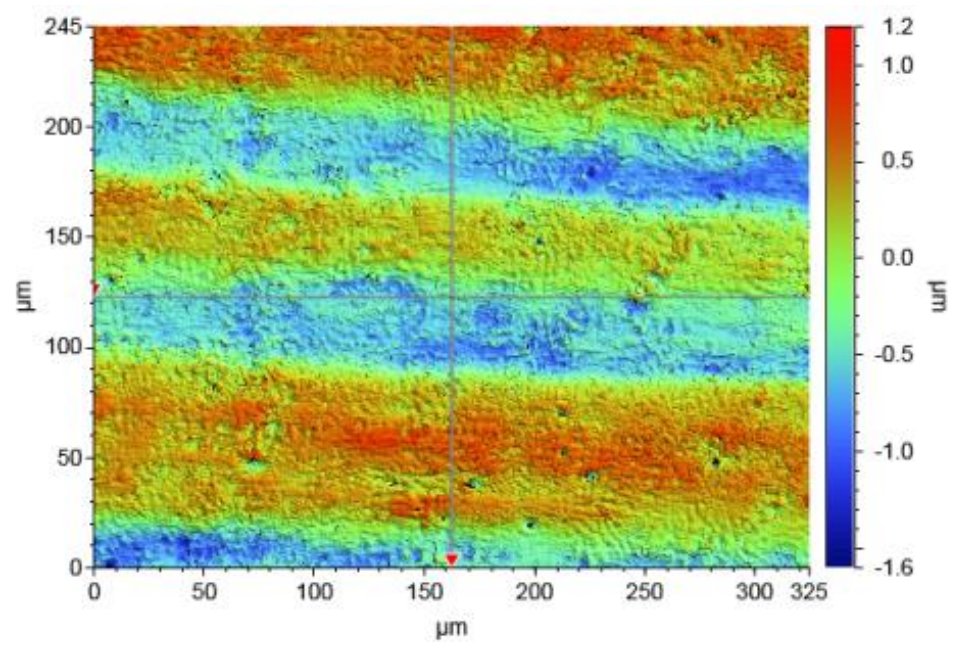

(b) 


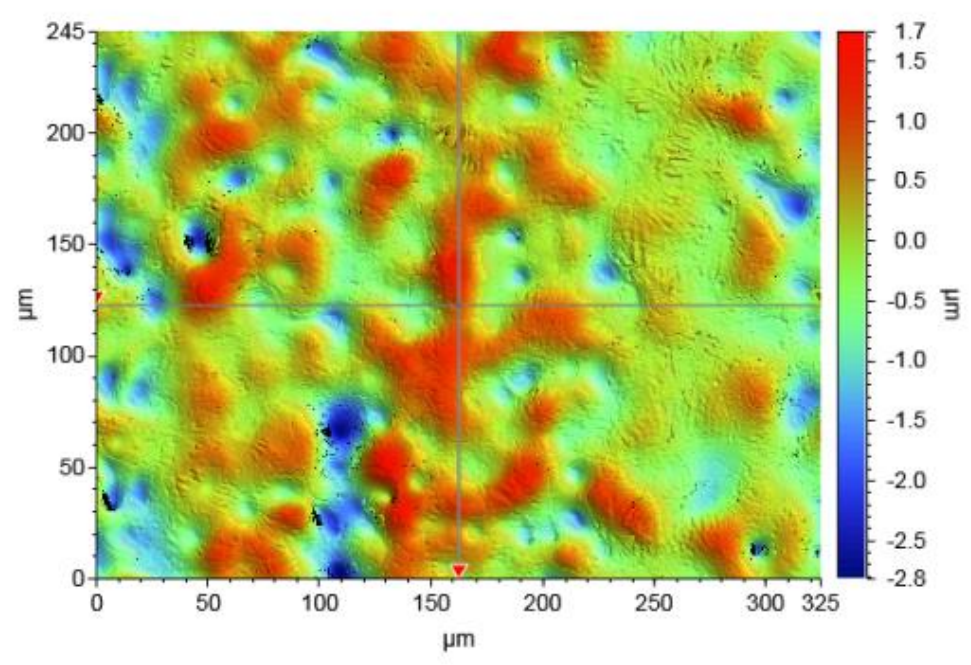

(c)

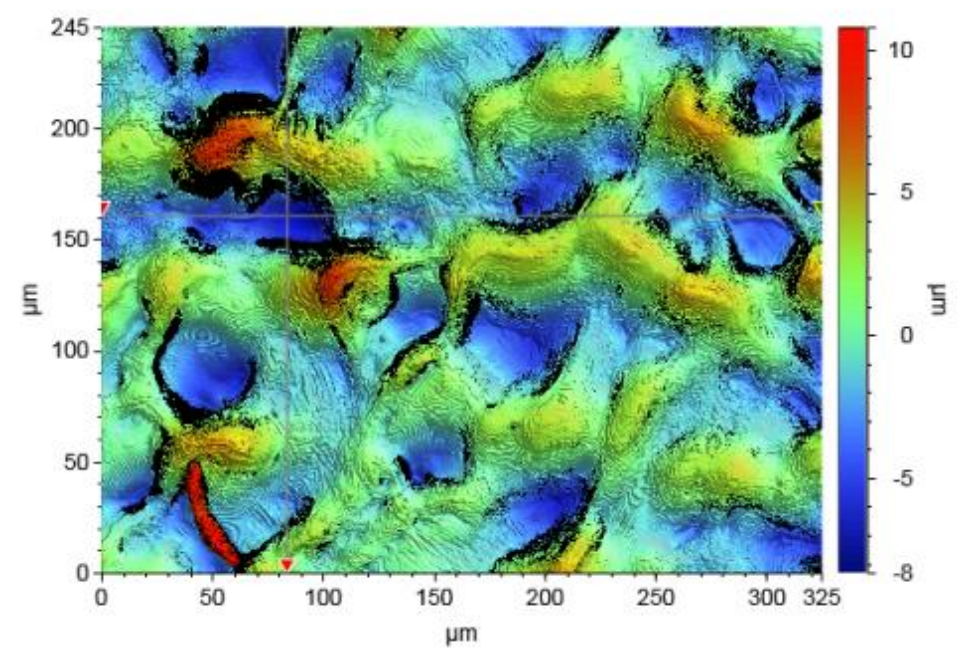

(d)

Figure 3: Surface profiles of the alloy obtained with the use of interferometer. (a) the asreceived, (b) laser-cleaned at $3.5 \mathrm{~J} / \mathrm{cm}^{2}$, (c) $7.1 \mathrm{~J} / \mathrm{cm}^{2}$ and (d) $11.3 \mathrm{~J} / \mathrm{cm}^{2}$. 


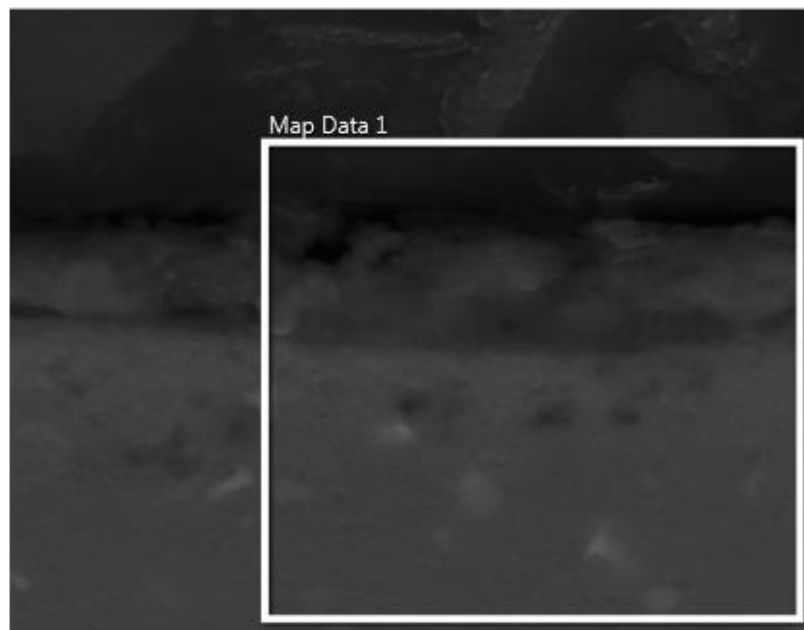

$M g \mathrm{~K} \alpha 1 \_2$
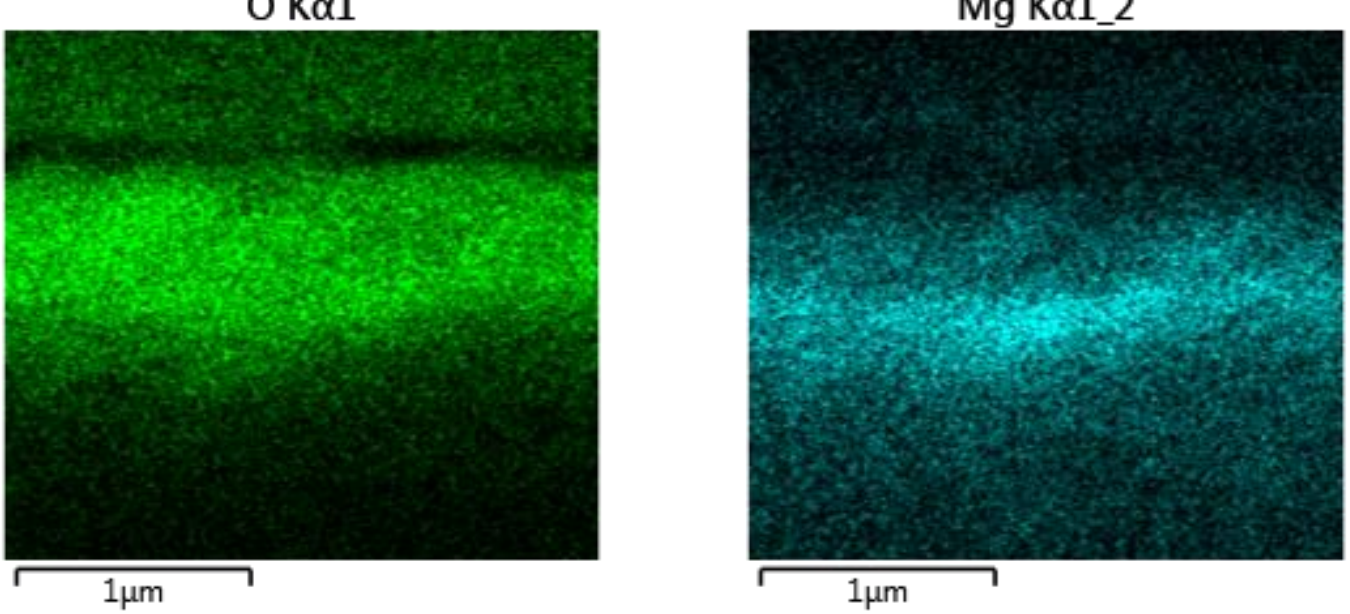

Al K $\alpha 1$

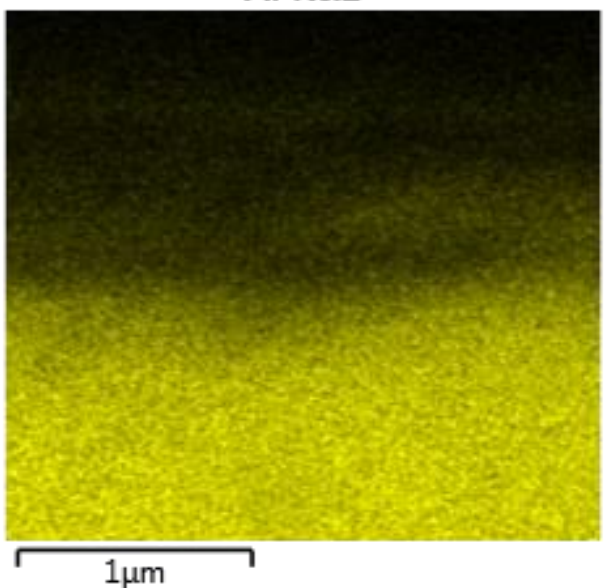

(a) 

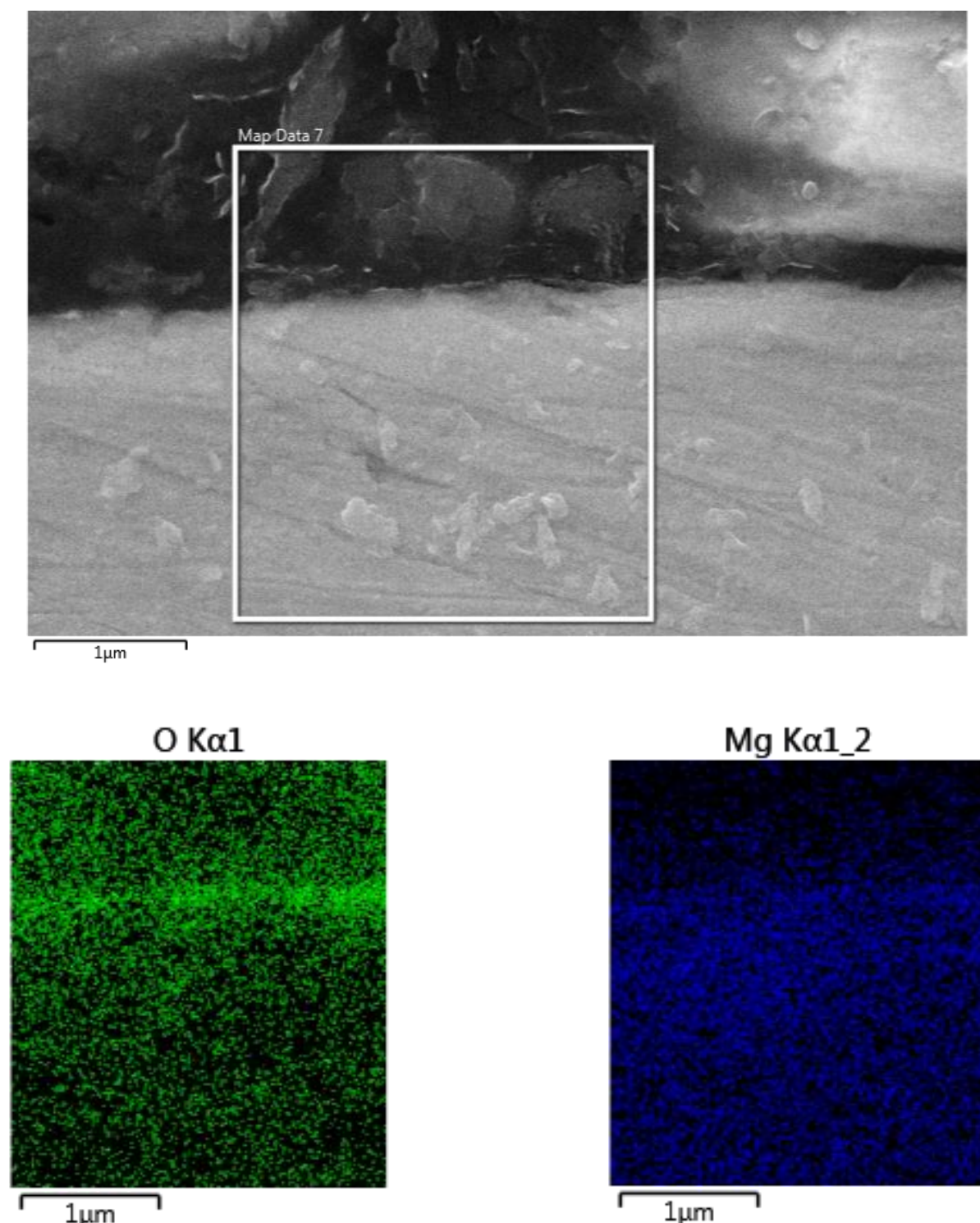

Mg Ka1_2

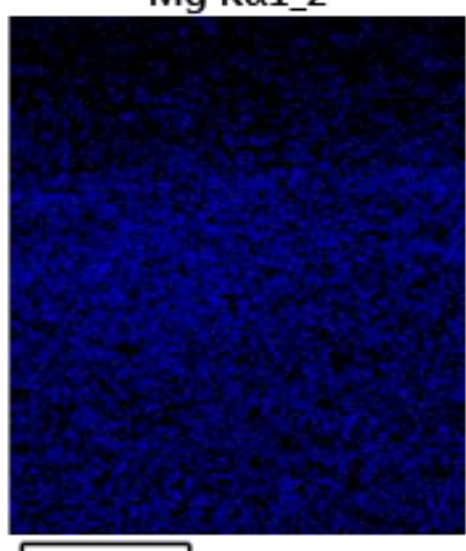

$1 \mu \mathrm{m}$

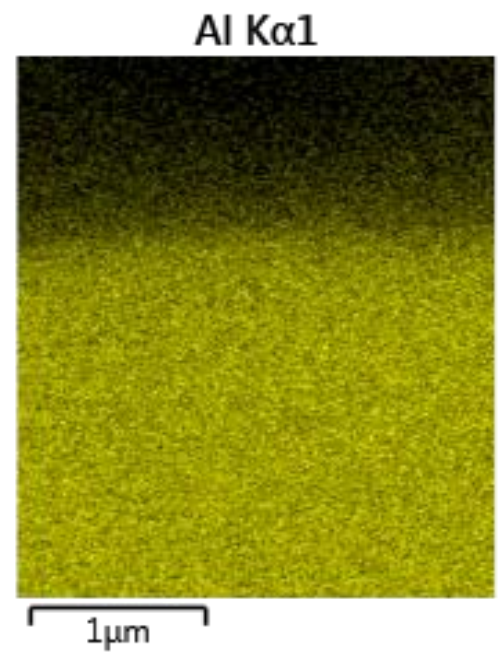

(b) 
Figure 4: SEM cross sectional micrographs of the as-received (a) and laser-cleaned at 7.1 $\mathrm{J} / \mathrm{cm}^{2}(\mathrm{~b})$, with EDS elemental mapping of $\mathrm{Al}, \mathrm{Mg}$ and $\mathrm{O}$. 


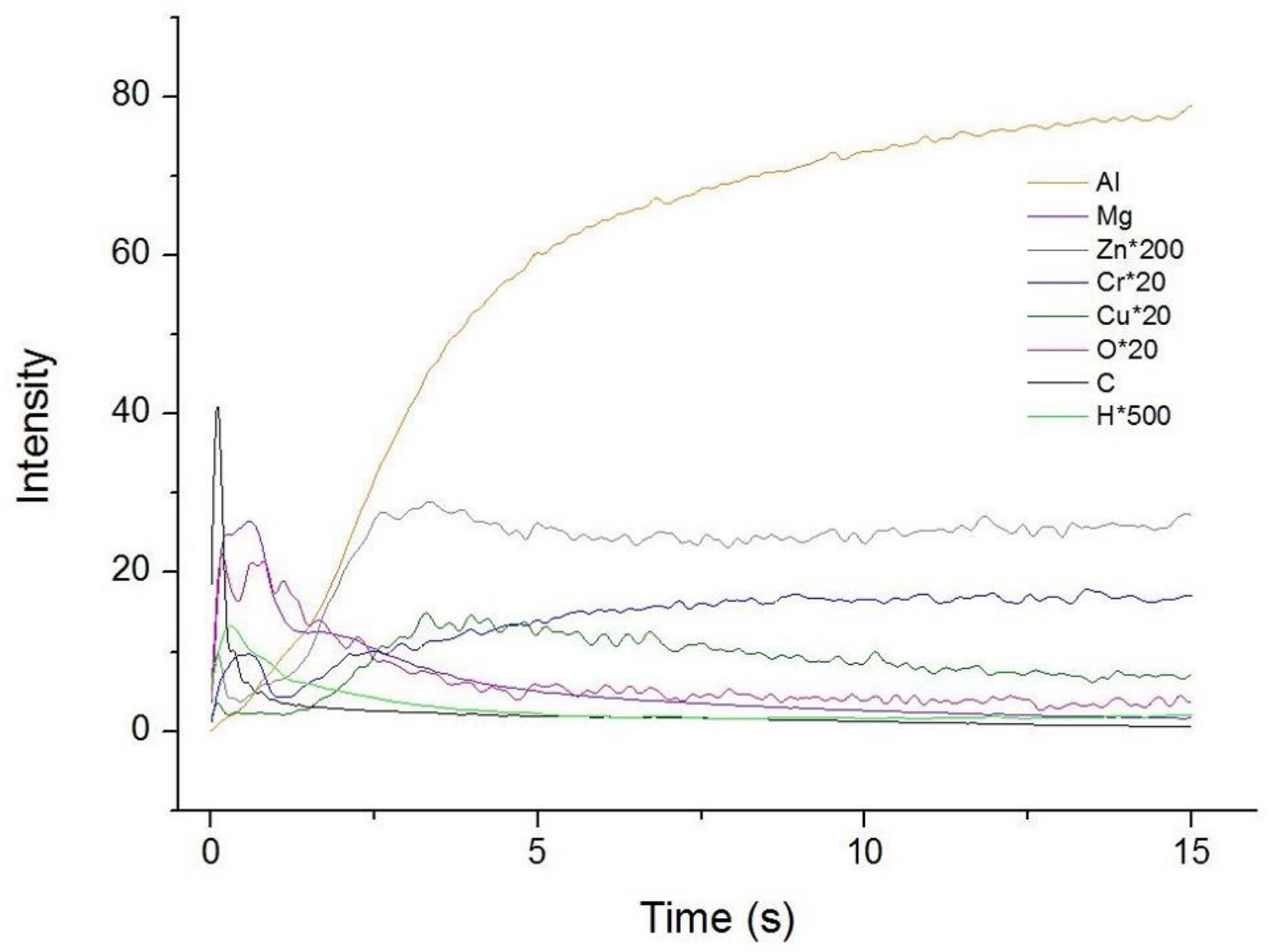

(a) 


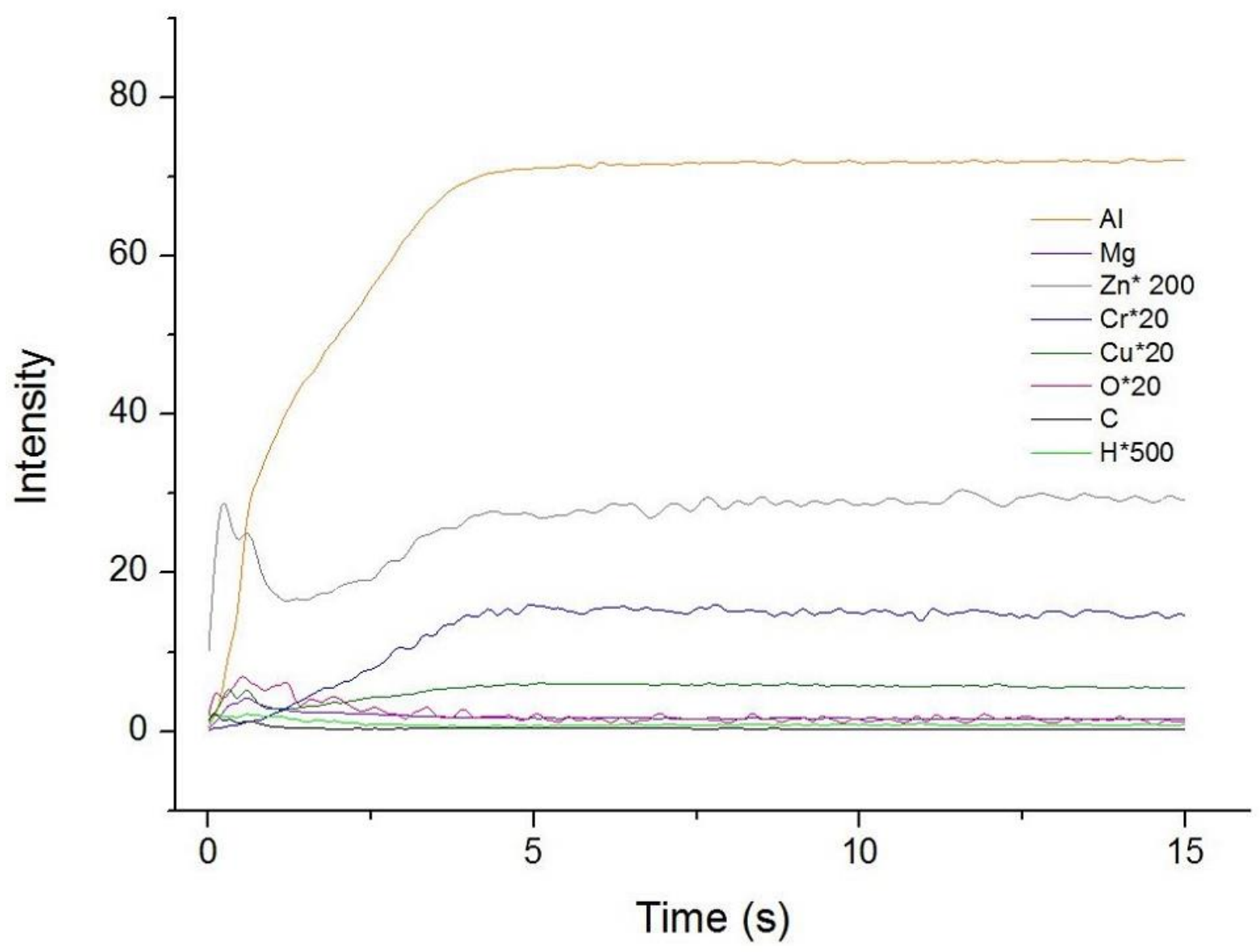

(b)

Figure 5: GDOES surface elemental depth profiles of (a) the as-received and (b) lasercleaned alloy at $7.1 \mathrm{~J} / \mathrm{cm}^{2}$. 
Survey/11

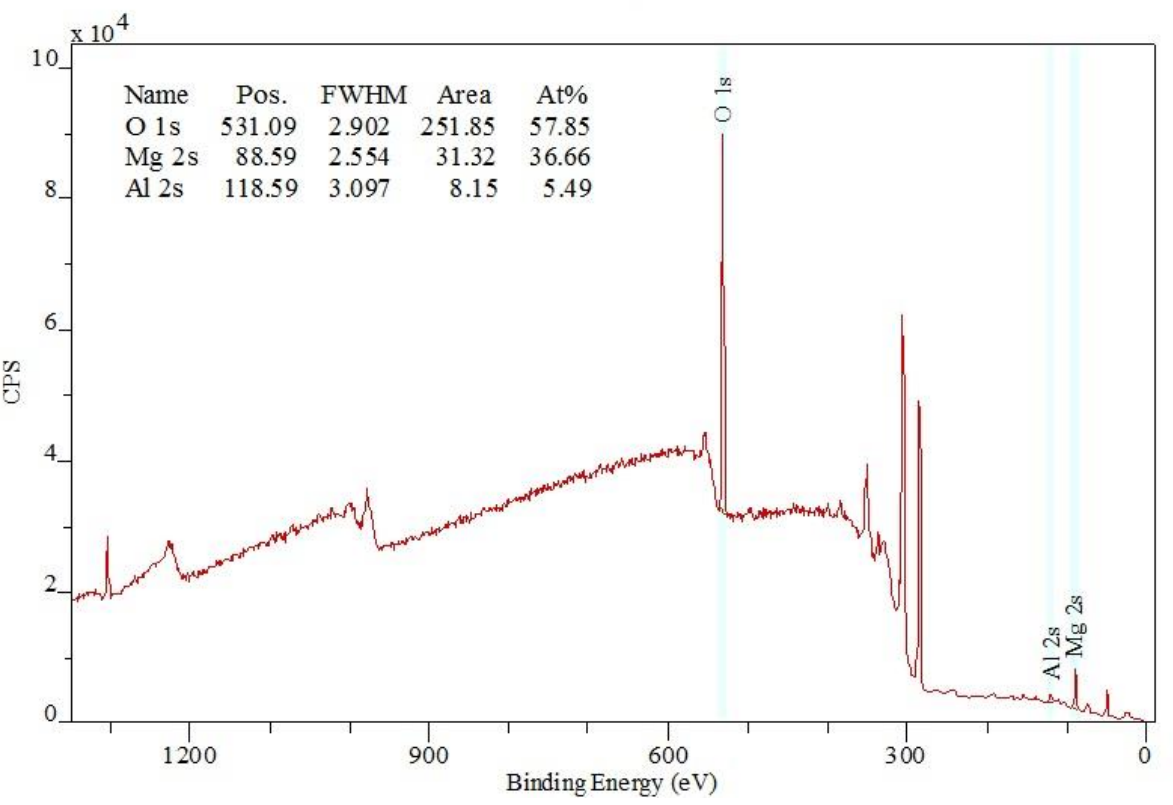

(a)

$\mathrm{Mg}$ 1s/12

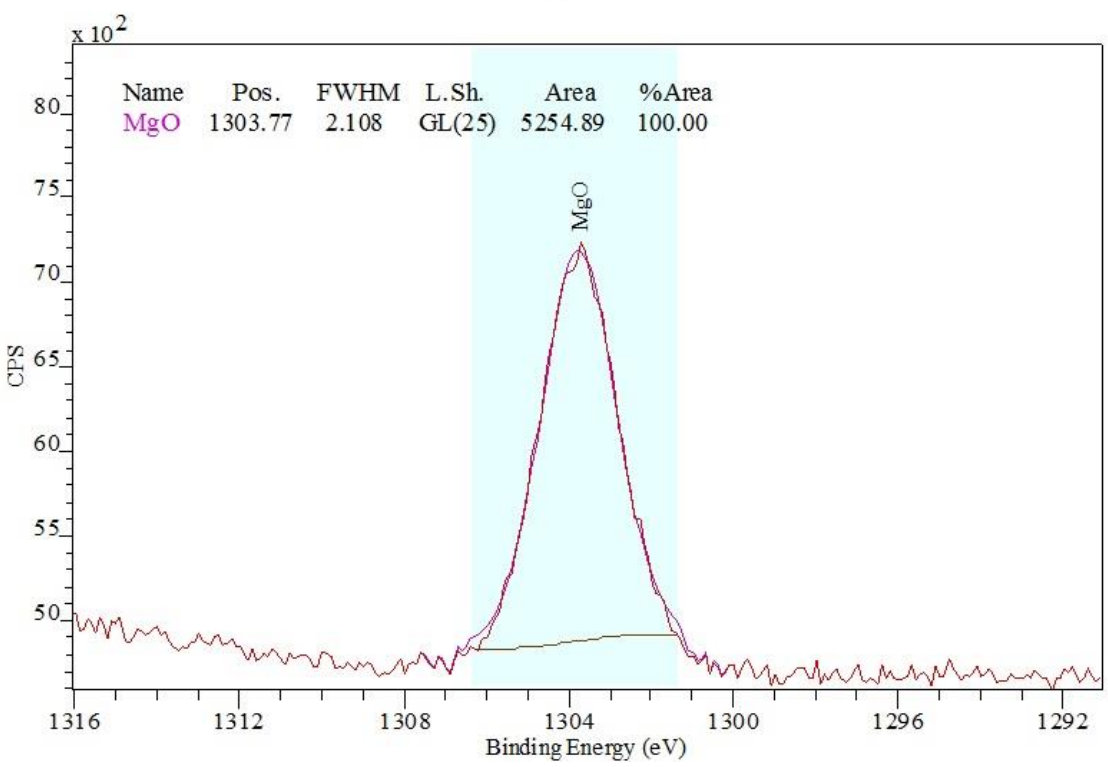

(b) 


\section{C $1 \mathrm{~s} / 15$}

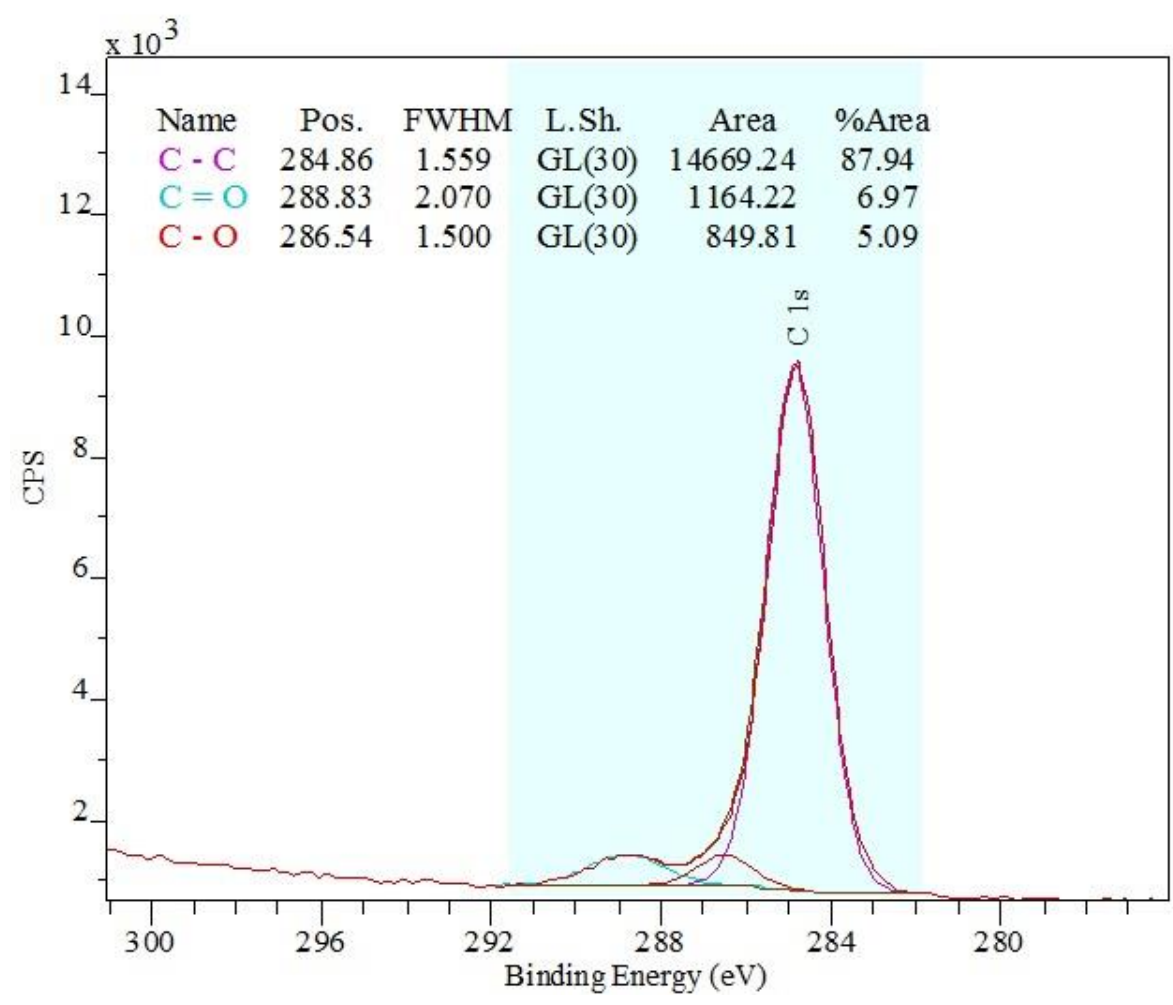

(c)

O $1 \mathrm{~s} / 14$

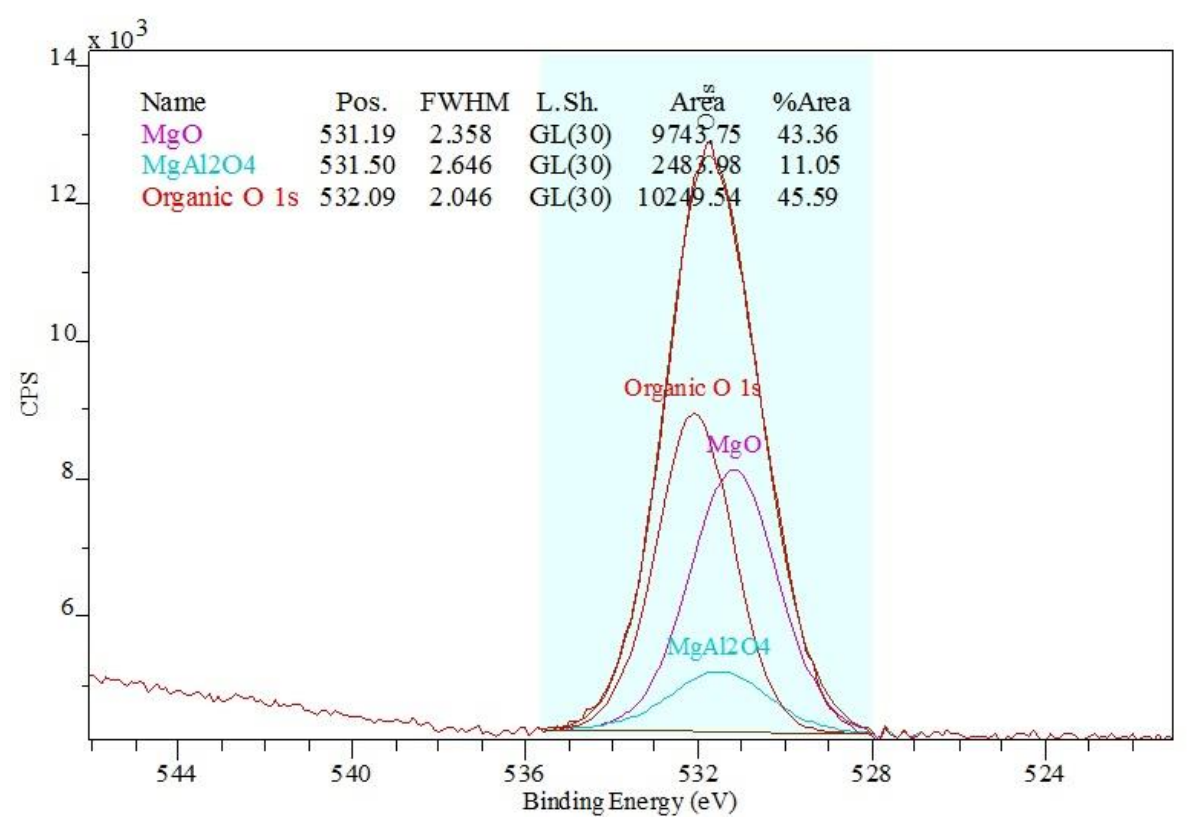

(d)

Figure 6: XPS spectra of the as-received alloy. (a) survey spectrum, (b) Mg 1s, (c) C 1s and (d) $01 \mathrm{~s}$. 
Survey/47

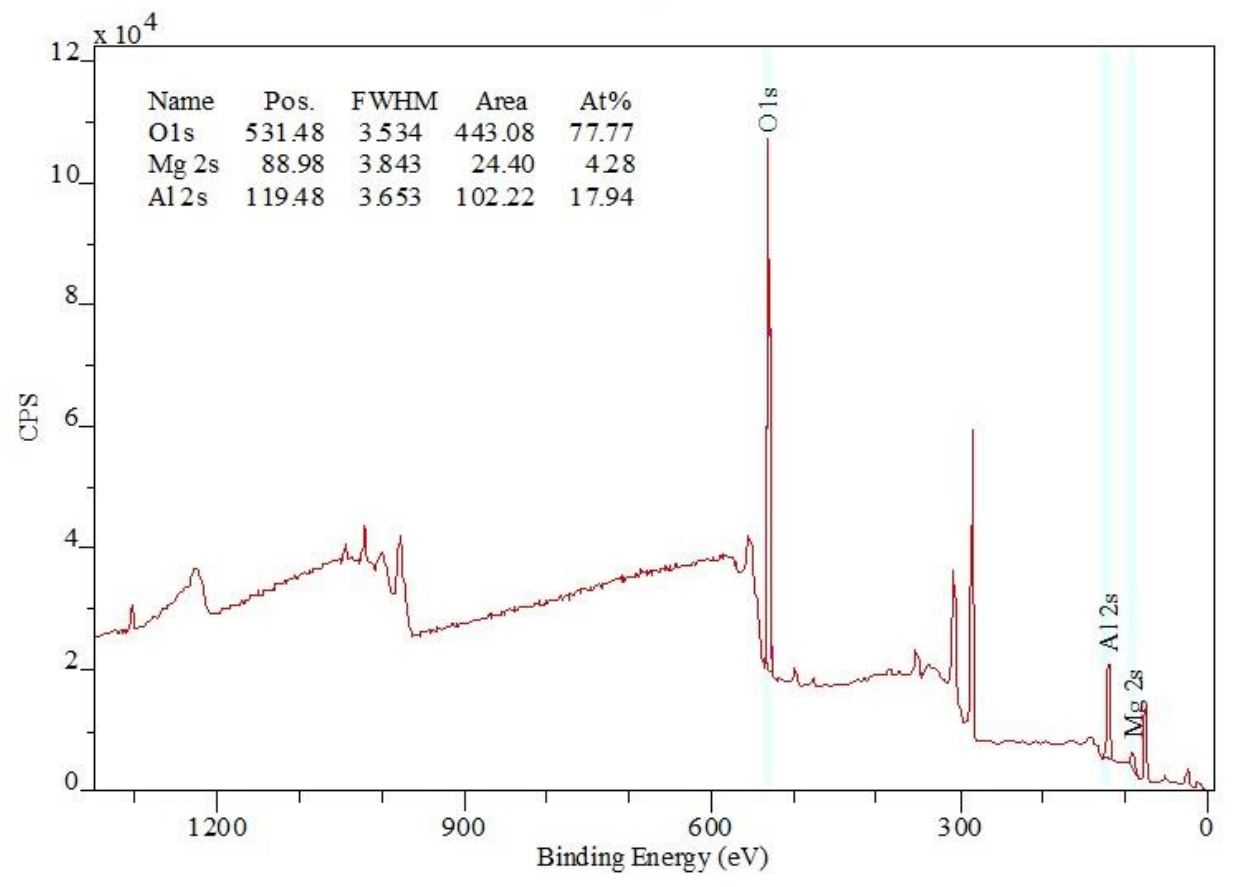

(a)

$\mathrm{Mg} \mathrm{1s/38}$

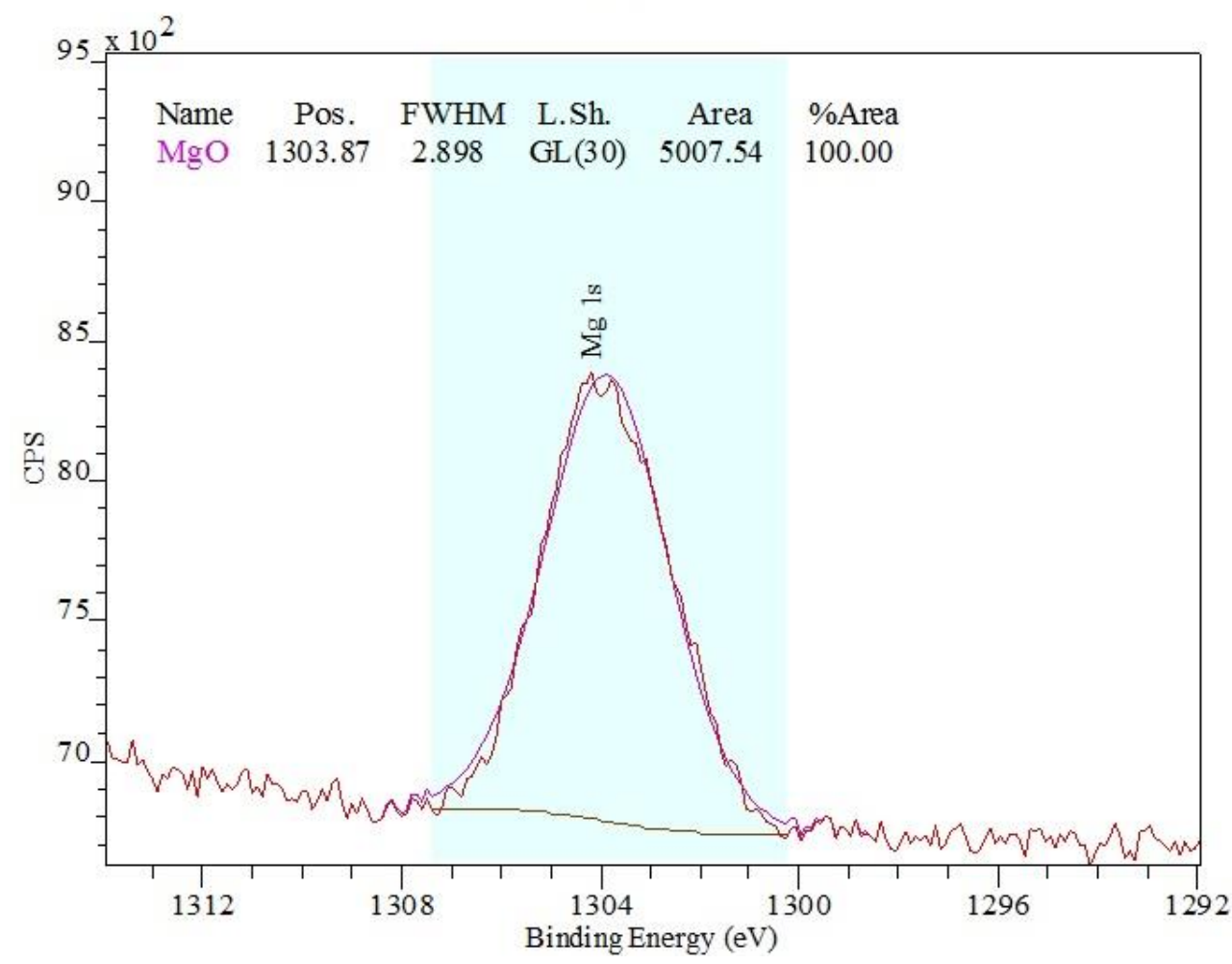

(b) 


\section{C $1 \mathrm{~s} / 44$}

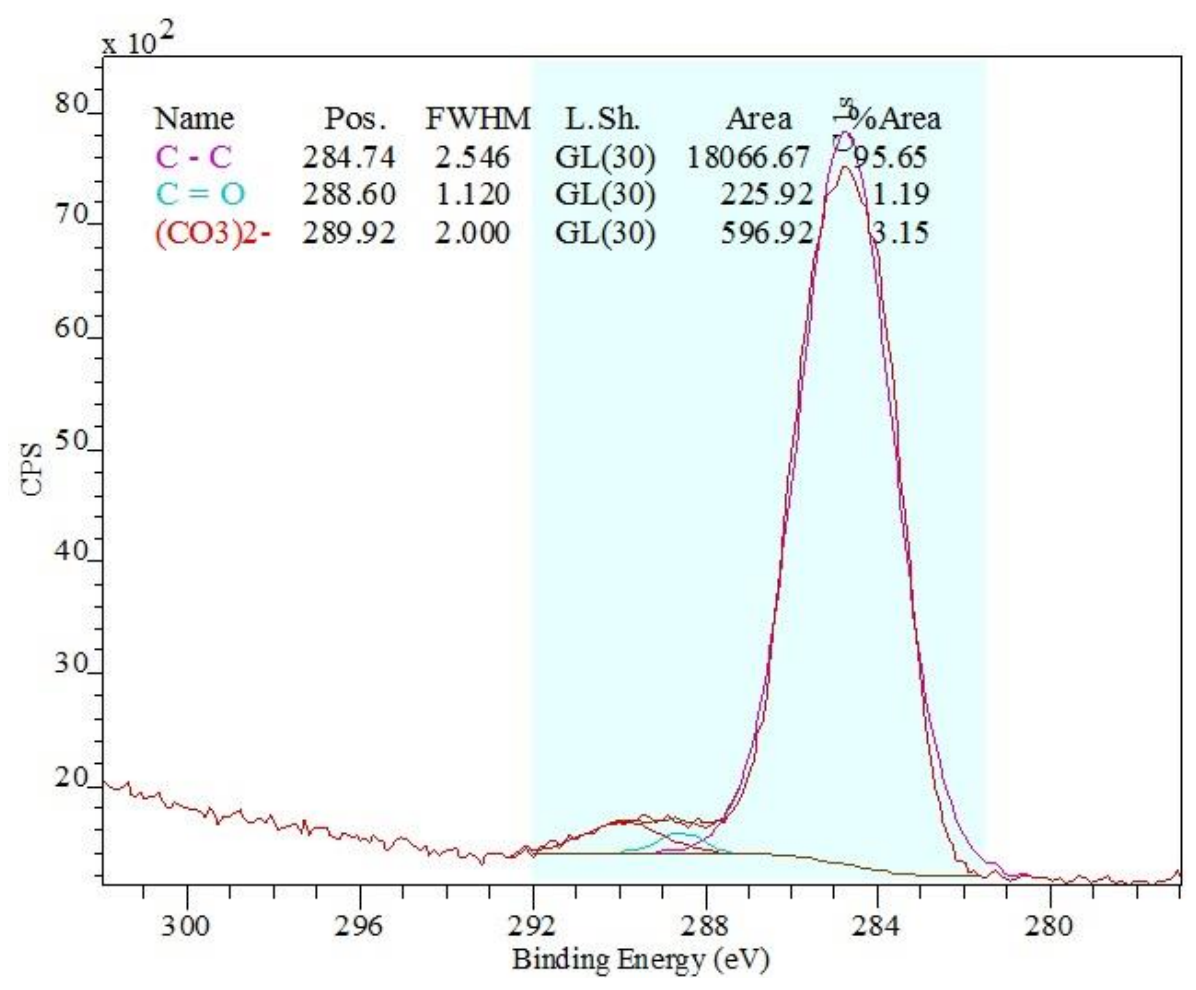

(c)

O $1 \mathrm{~s} / 42$

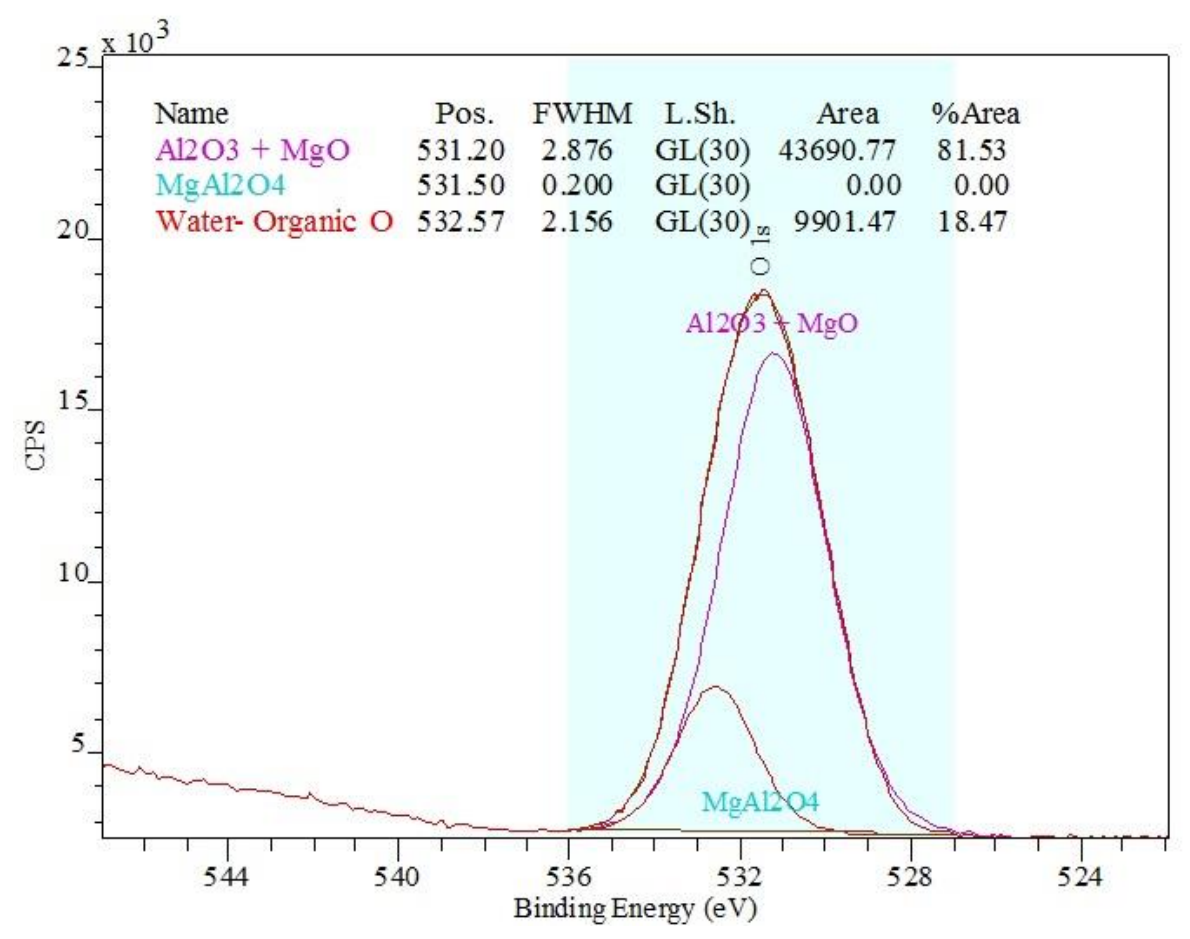

(d)

Figure 7: XPS spectra of the laser-cleaned at $7.1 \mathrm{~J} / \mathrm{cm}^{2}$. (a) survey spectrum, (b) $\mathrm{Mg} 1 \mathrm{~s}$, (c) C $1 \mathrm{~s}$ and (d) $01 \mathrm{~s}$. 


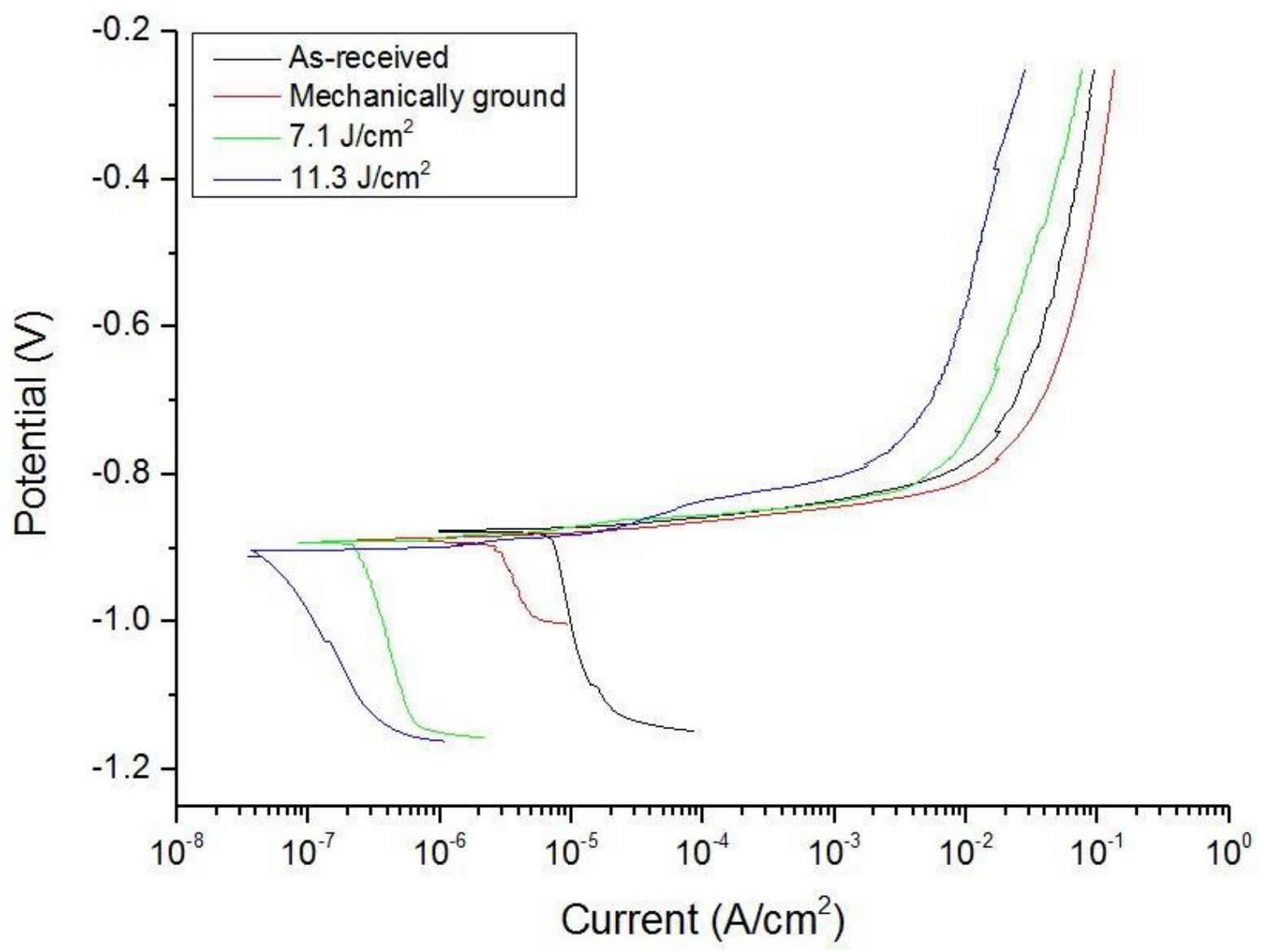

Figure 8: Potentiodynamic curves of the as-received, mechanically ground and laser-cleaned alloy at $7.1 \mathrm{~J} / \mathrm{cm}^{2}$ and $11.3 \mathrm{~J} / \mathrm{cm}^{2}$ in $3.5 \mathrm{wt} . \% \mathrm{NaCl}$ solution. 


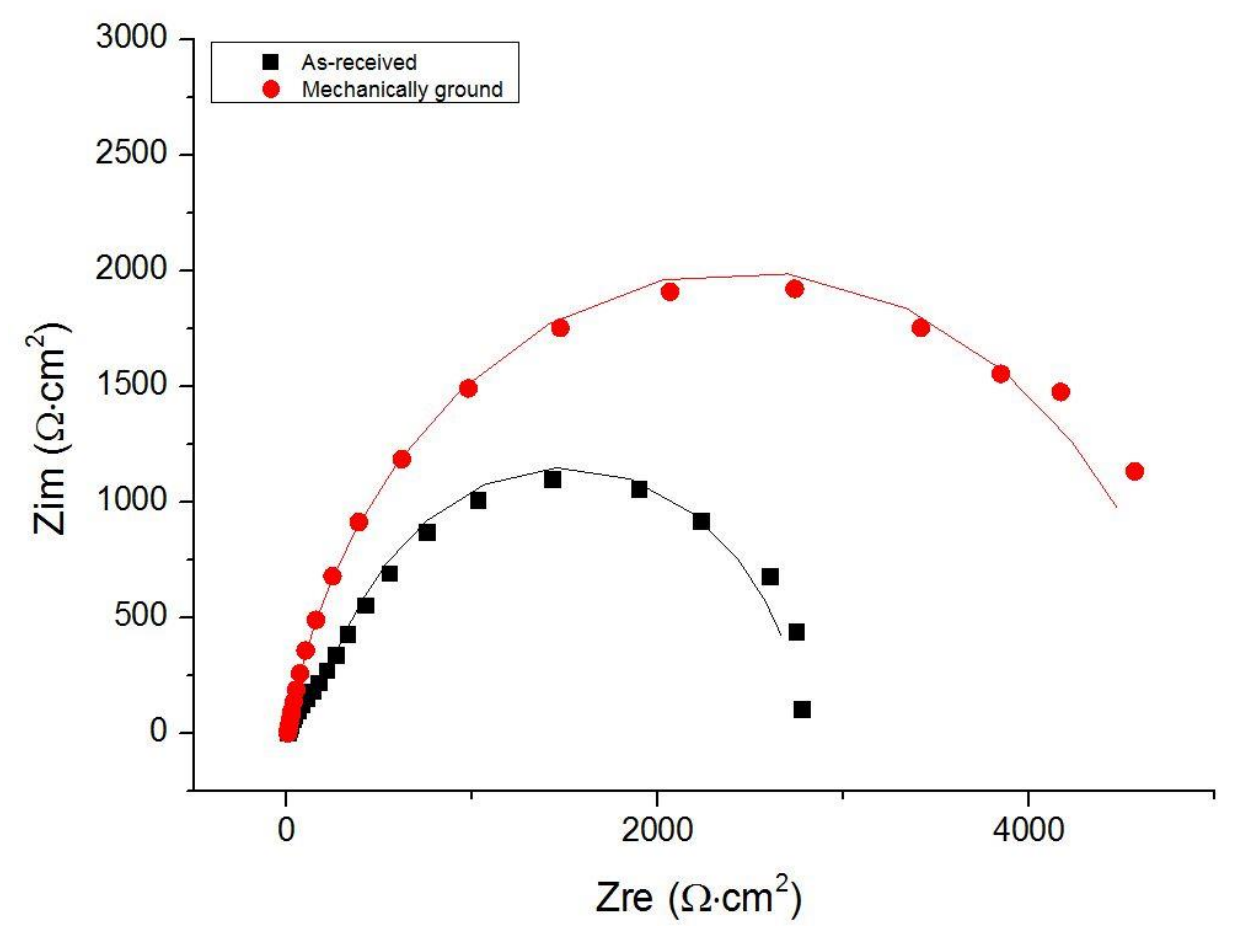

(a)

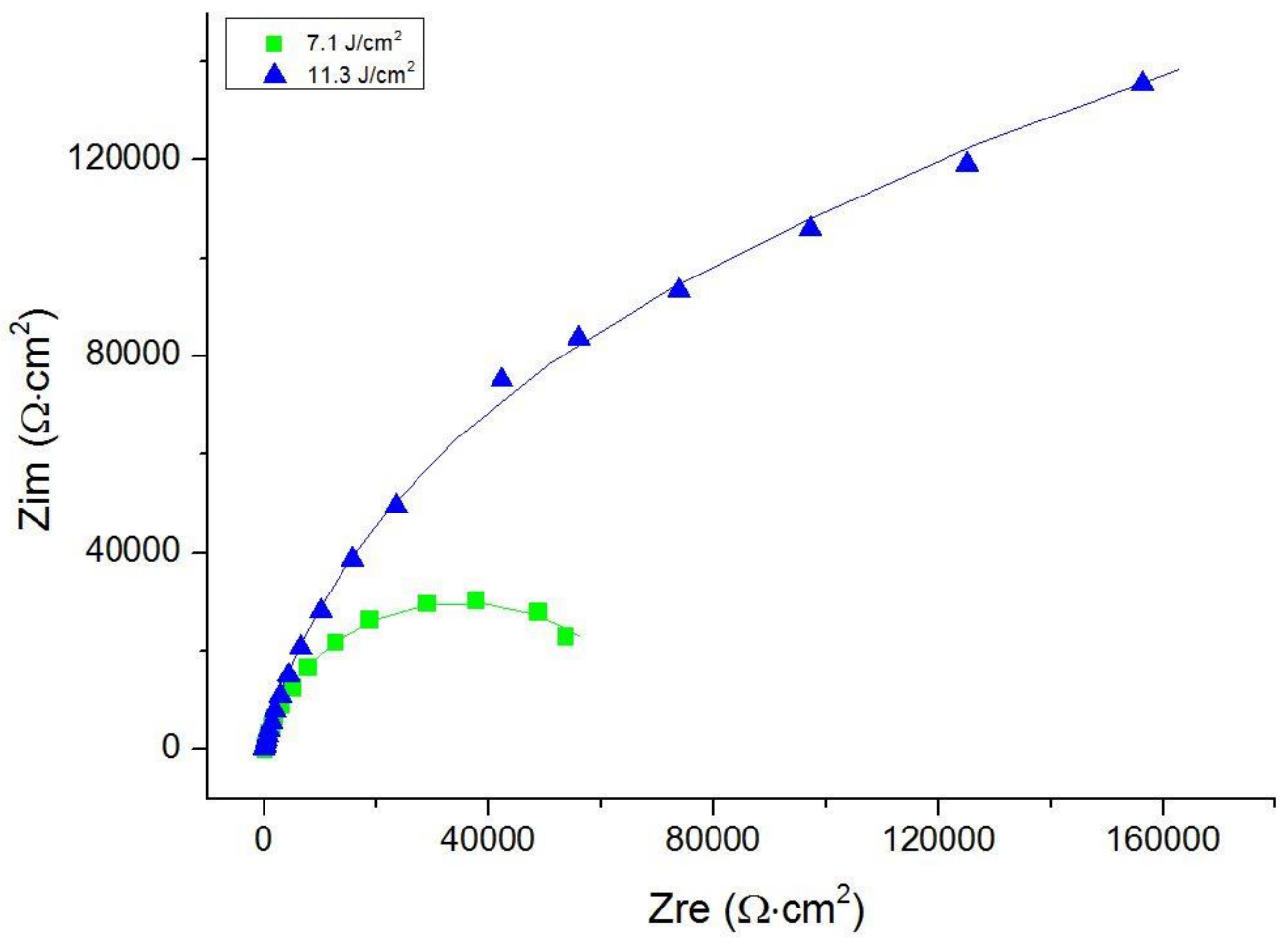

(b) 


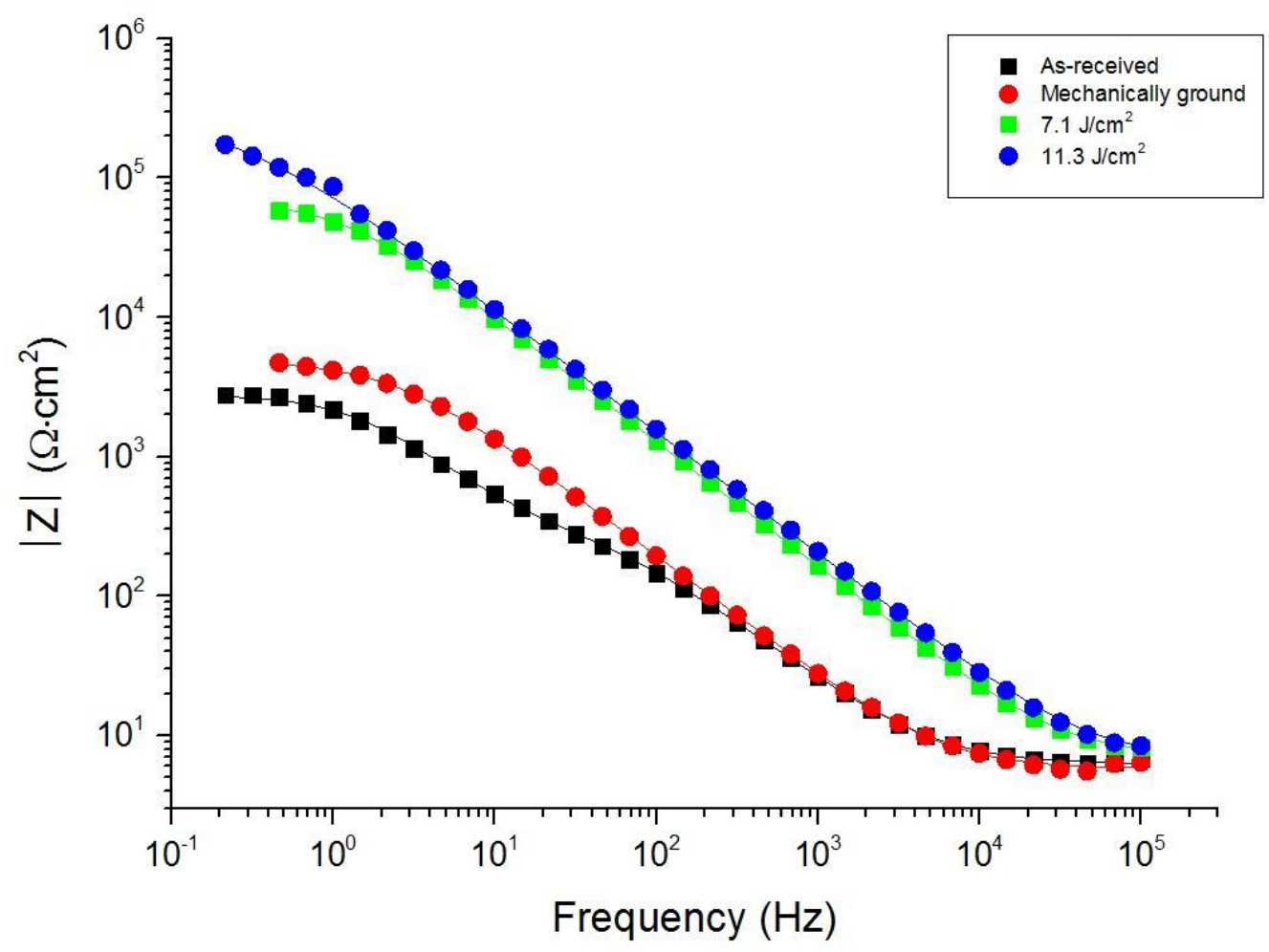

(c)

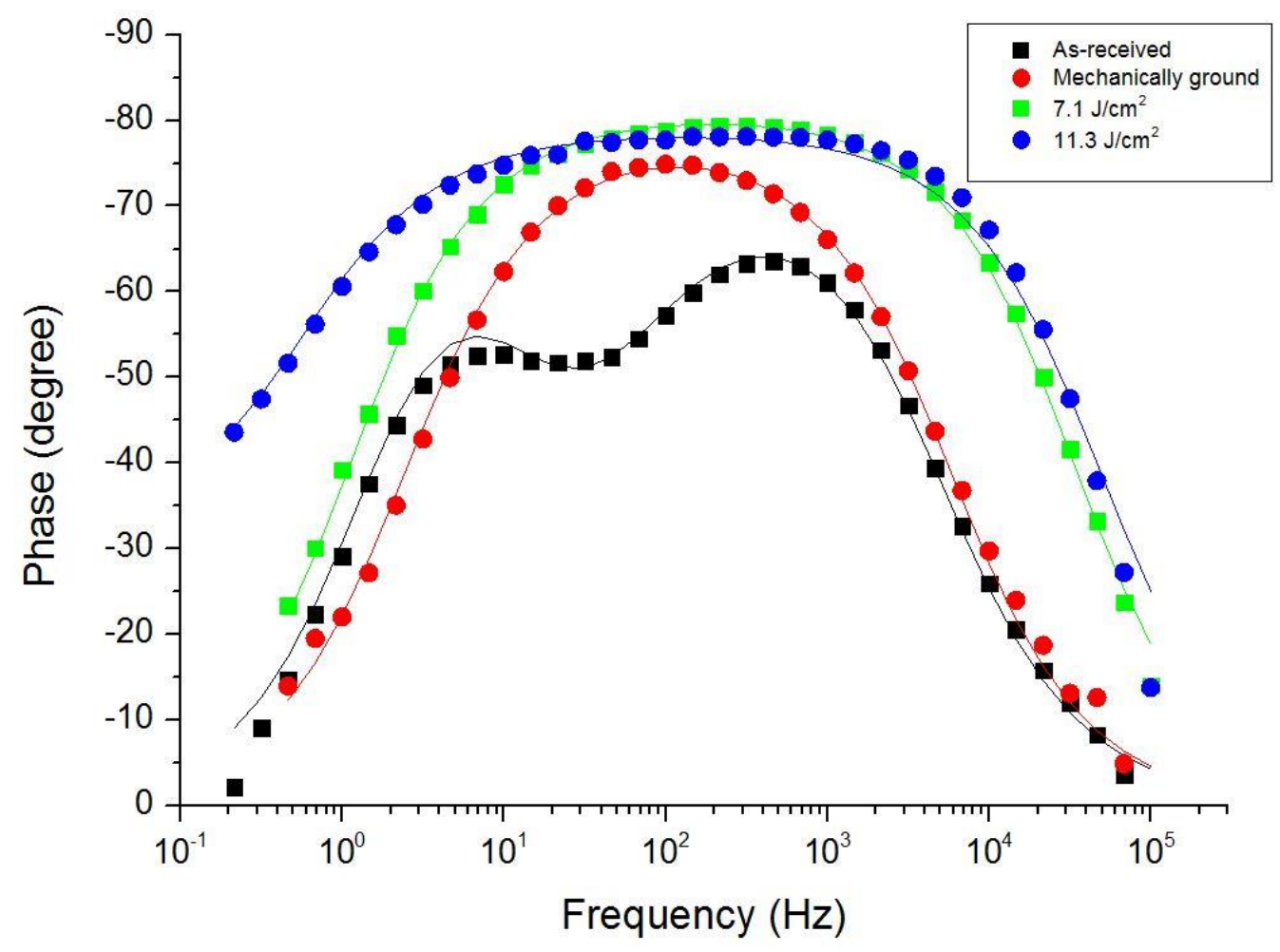

(d) 


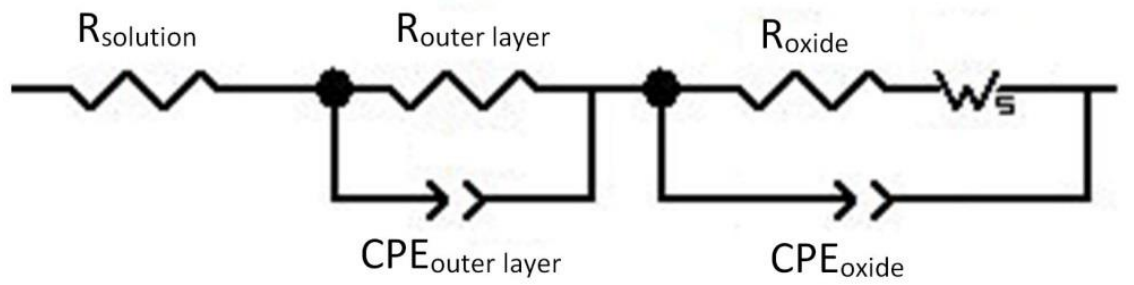

(e)

Figure 9: EIS data obtained in $3.5 \mathrm{wt} . \% \mathrm{NaCl}$ solution. (a) Nyquist plots and fitting curves of the as-received and mechanically ground, (b) Nyquist plots and fitting curves of lasercleaned at $7.1 \mathrm{~J} / \mathrm{cm}^{2}$ and $11.3 \mathrm{~J} / \mathrm{cm}^{2}$, (c) Bode plots-impedance, (d) Bode plots-phase angle and (e) Equivalent circuits of the EIS spectra. 

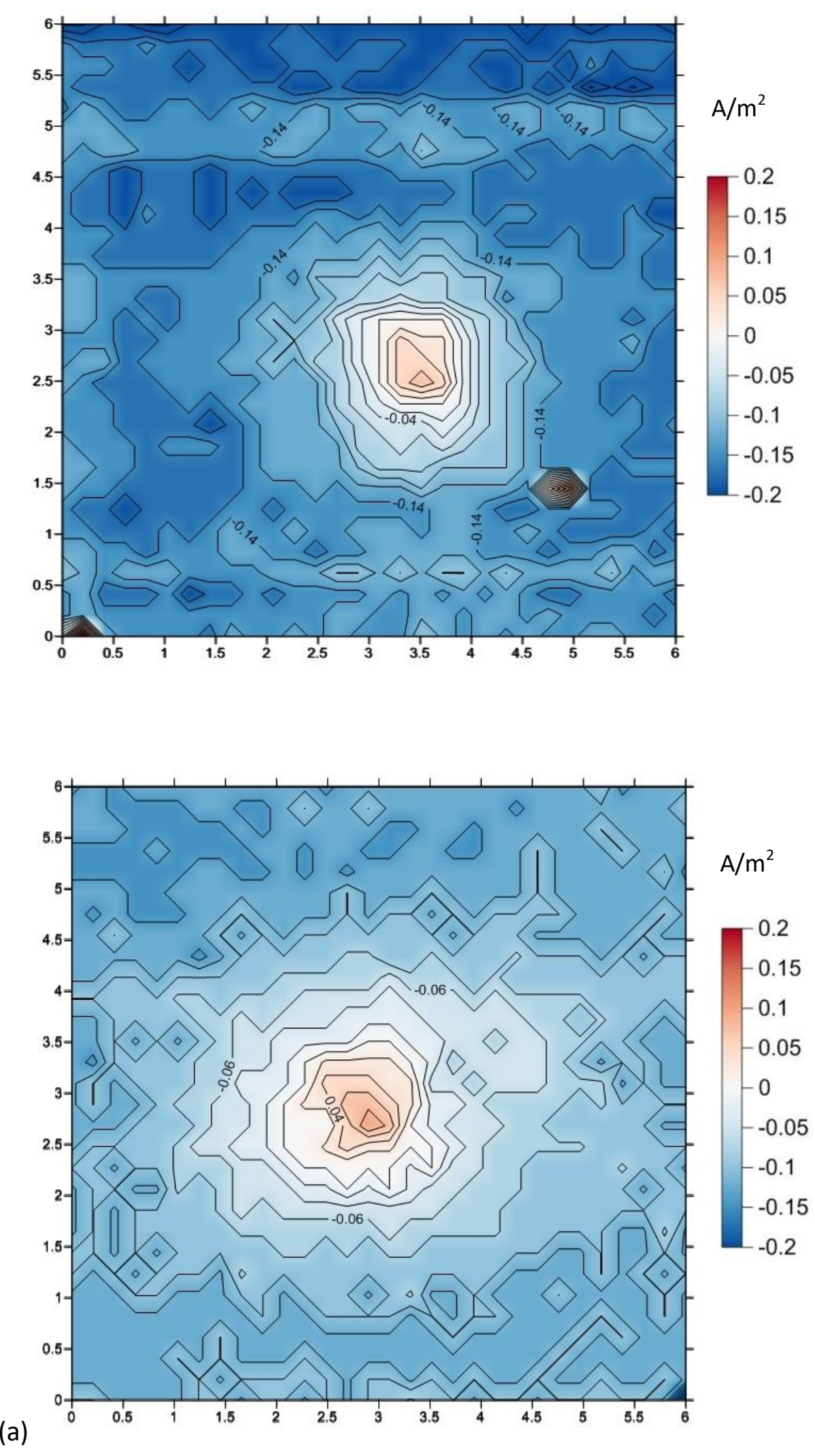

(b) 


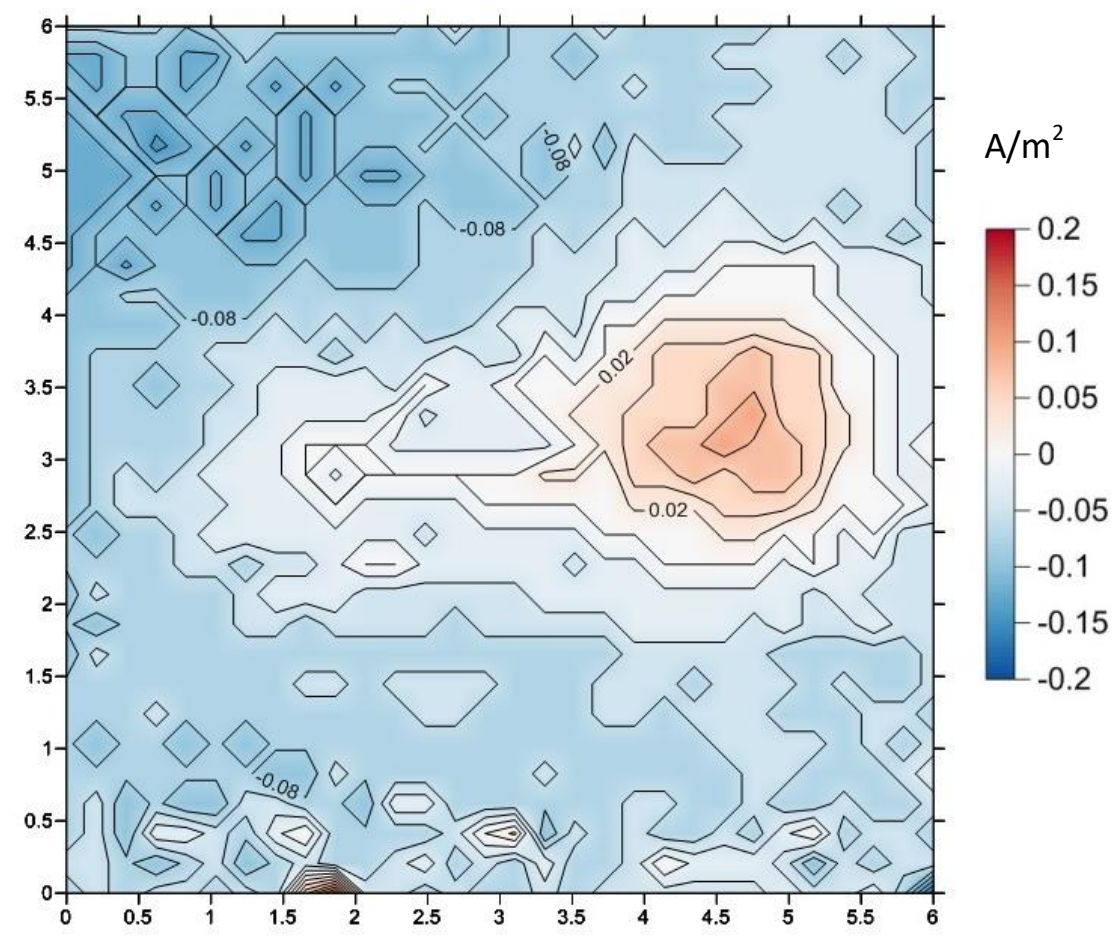

(c)

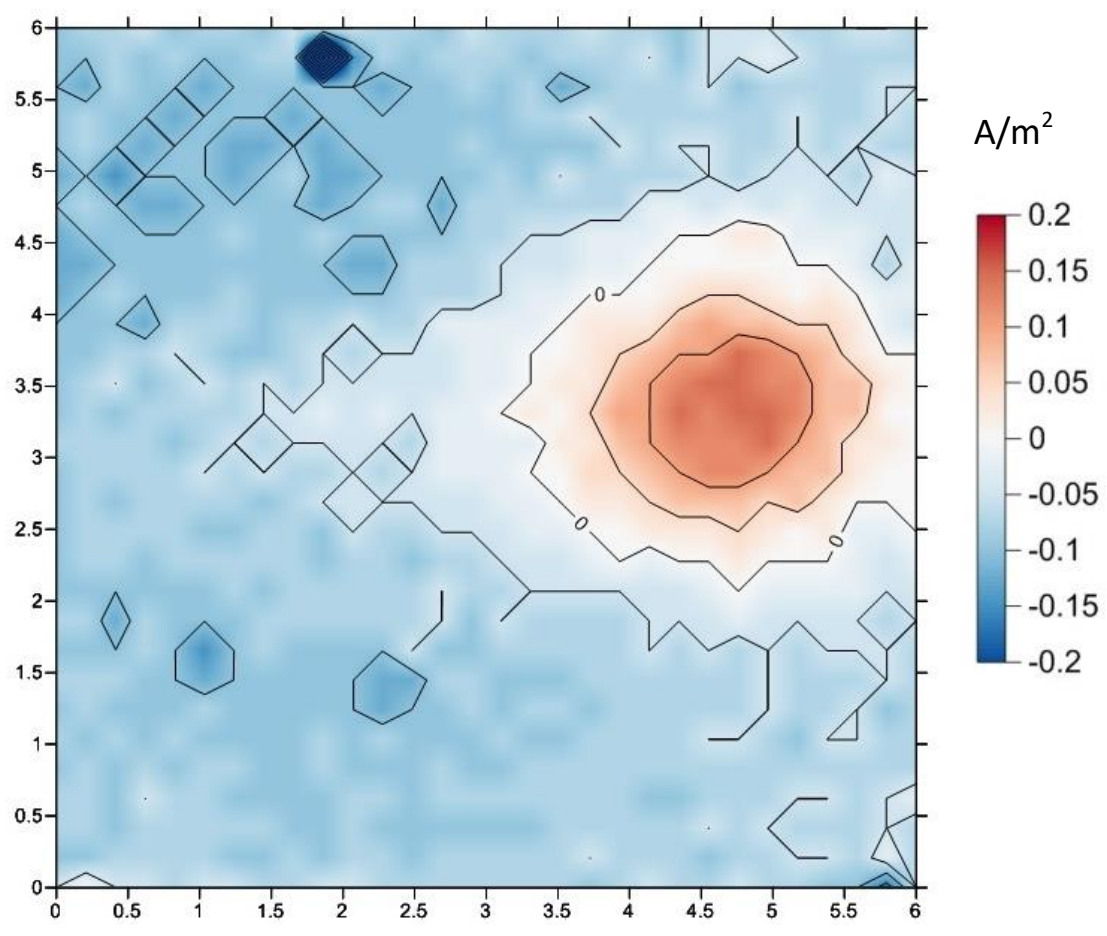

(d)

Figure 10: SVET maps of the as-received alloy with different immersion time in $3.5 \mathrm{wt} . \%$ $\mathrm{NaCl}$ solution and tested area of $6 \mathrm{mmx} 6 \mathrm{~mm}$. (a) $15 \mathrm{~min}$, (b) $4 \mathrm{~h}$, (c) $12 \mathrm{~h}$ and $20 \mathrm{~h}$. 


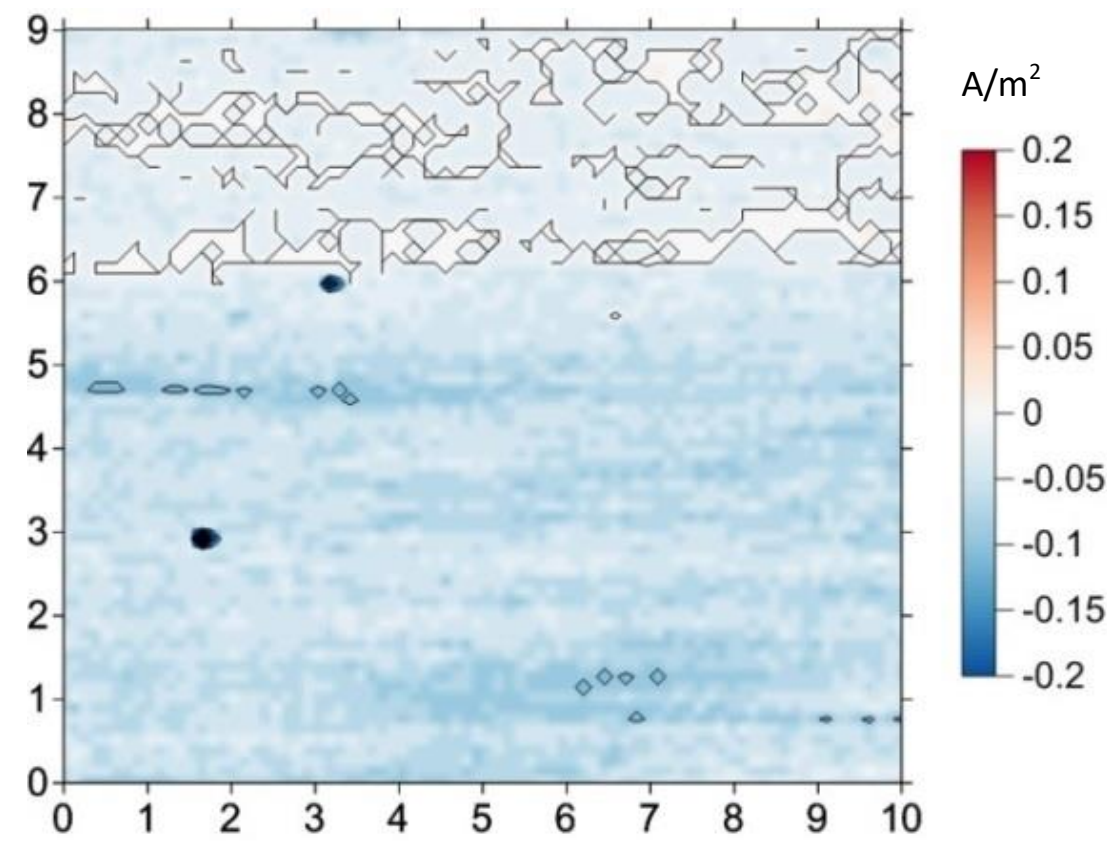

(a)

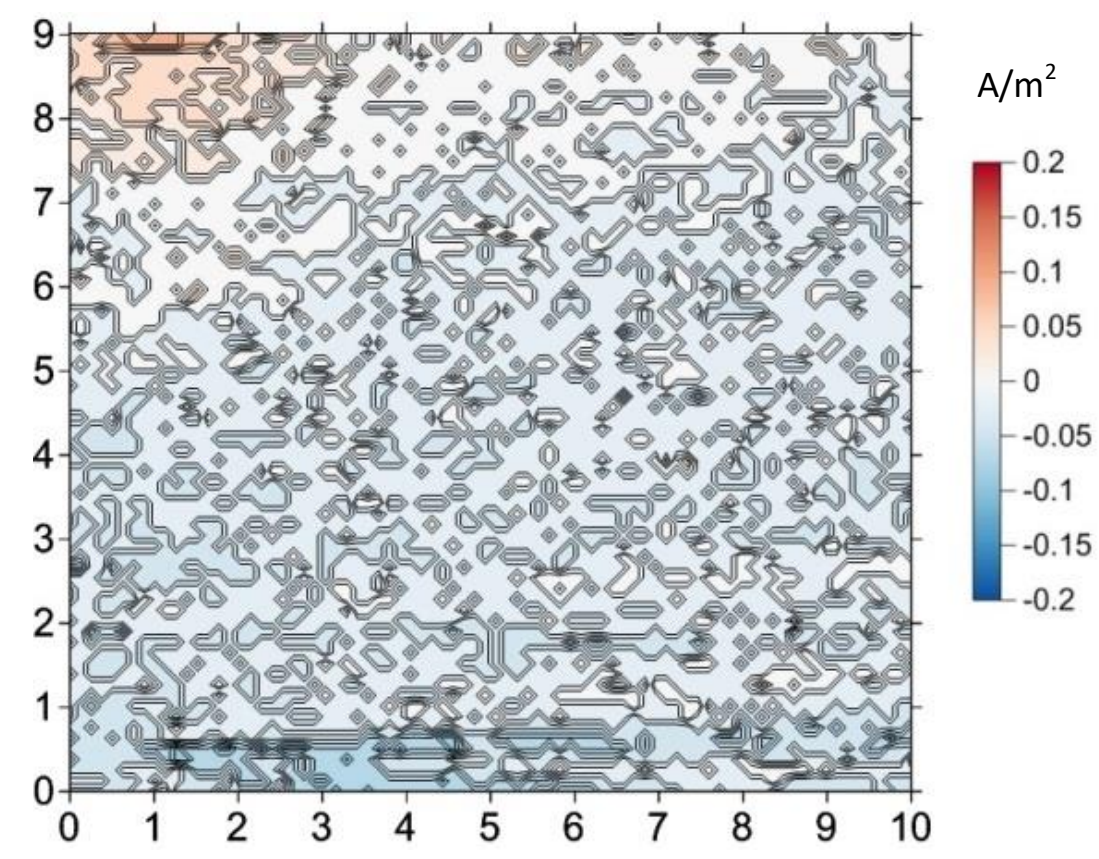

(b) 


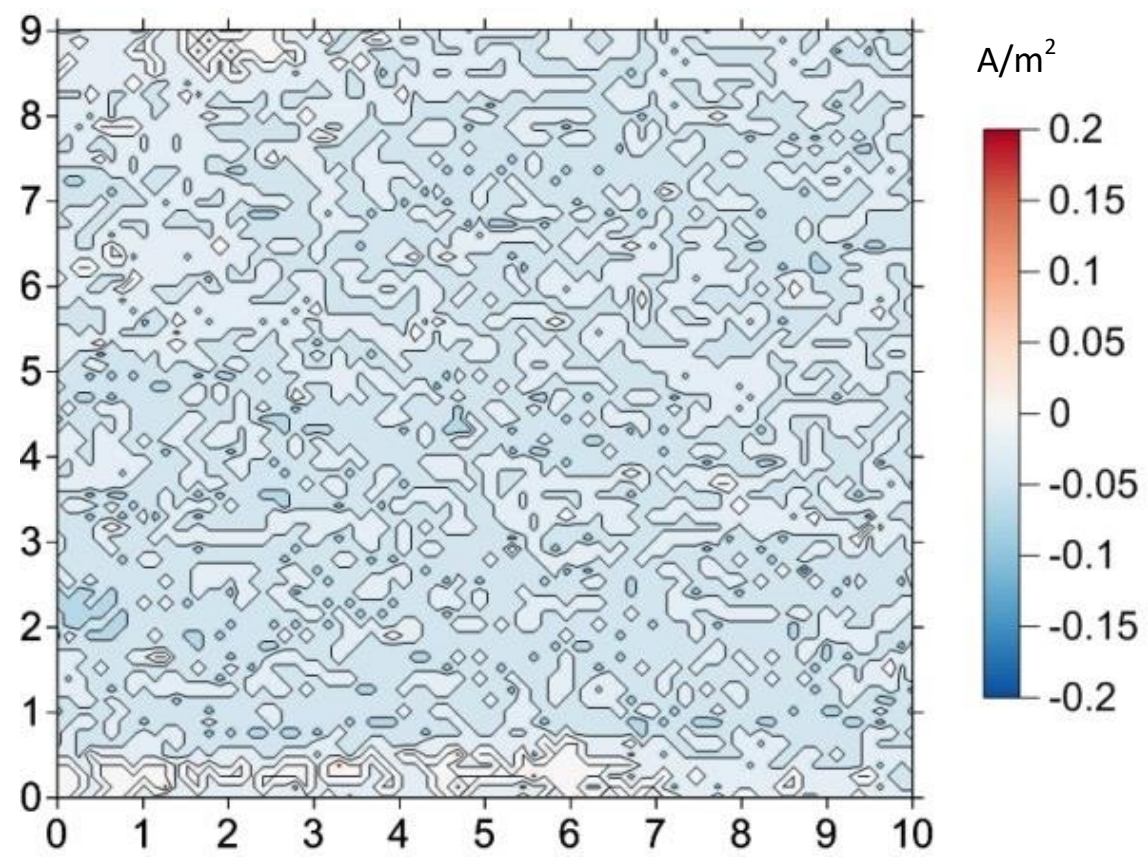

(c)

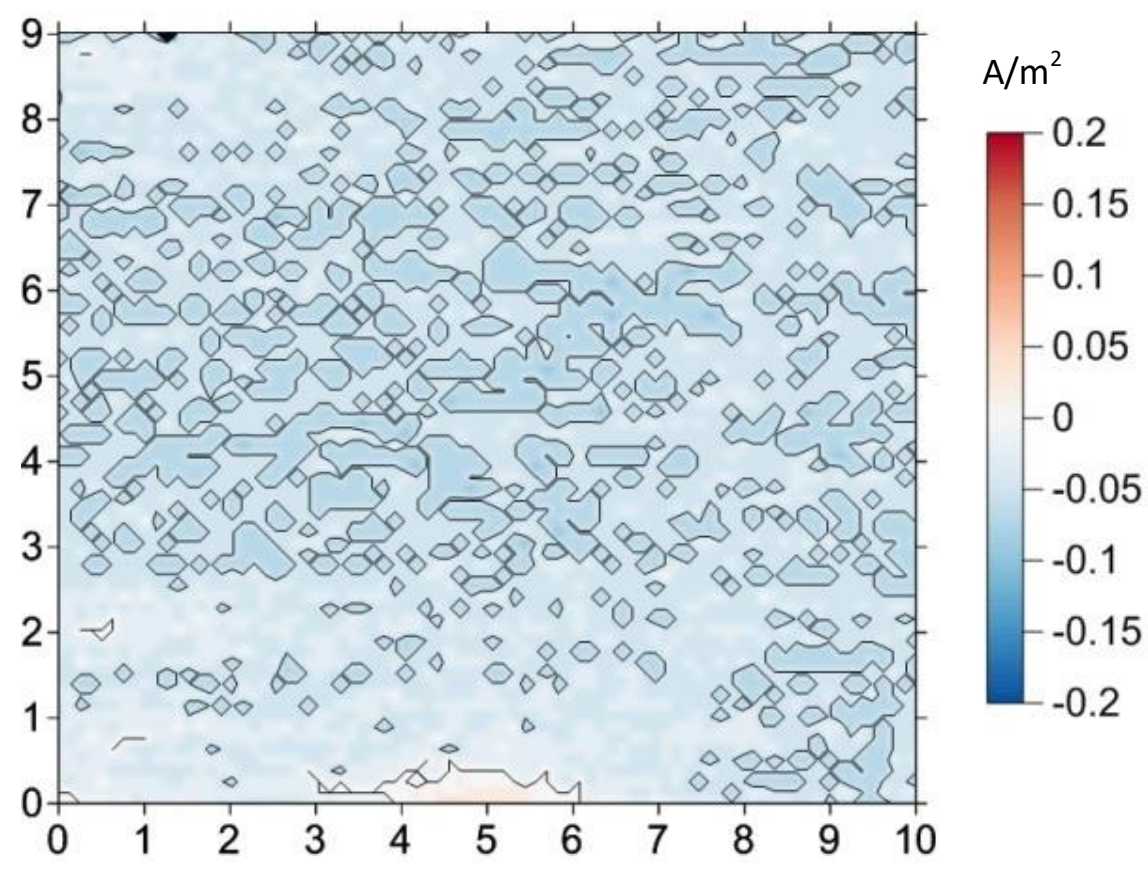

(d)

Figure 11: SVET maps of the laser-cleaned at $7.1 \mathrm{~J} / \mathrm{cm}^{2}$ with different immersion time in 3.5 wt.\% $\mathrm{NaCl}$ solution and tested area of $9 \mathrm{~mm} \times 10 \mathrm{~mm}$. (a) $15 \mathrm{~min}$, (b) $4 \mathrm{~h}$, (c) $12 \mathrm{~h}$ and (d) $20 \mathrm{~h}$. 
Table 1: EIS parameters of the surfaces before and after laser cleaning, obtained by fitting the Nyquist plots with the equivalent circuit in 3.5 wt.\% $\mathrm{NaCl}$ solution.

\begin{tabular}{|l|l|l|l|l|}
\hline Samples & As-received & Mechanically ground & Laser-cleaned at $7.1 \mathrm{~J} / \mathrm{cm}^{2}$ & Laser-cleaned at $11.3 \mathrm{~J} / \mathrm{cm}^{2}$ \\
\hline $\mathrm{R}_{\text {solution, } \Omega . \mathrm{cm}^{2}}$ & 6.179 & 5.727 & 7.145 & 7.041 \\
\hline $\mathrm{R}_{\text {outer layer, } \Omega . \mathrm{cm}^{2}}$ & 220.900 & - & - & - \\
\hline $\mathrm{CPE}_{\text {outer layer }}-\mathrm{T}, \Omega^{-1} \mathrm{~cm}^{-2} \mathrm{~s}^{\mathrm{n}}$ & 34.876 & - & - & - \\
\hline $\mathrm{CPE}_{\text {outer layer }}-\mathrm{P}$ & 0.839 & - & - & - \\
\hline $\mathrm{C}_{\text {outer layer, }} \mu \mathrm{F} / \mathrm{cm}^{2}$ & 136.364 & & & \\
\hline $\mathrm{R}_{\text {oxide, }} \Omega \cdot \mathrm{cm}^{2}$ & 2561.000 & 4898.000 & 70421.000 & 182100.000 \\
\hline $\mathrm{CPE}$ oxide $-\mathrm{T}, \Omega^{-1} \mathrm{~cm}^{-2} \mathrm{~s}^{\mathrm{n}}$ & 52.316 & 18.701 & 2.419 & 2.158 \\
\hline $\mathrm{CPE} \mathrm{E}_{\text {oxide }}-\mathrm{P}$ & 0.925 & 0.871 & 0.896 & 0.885 \\
\hline $\mathrm{C}_{\text {oxide }} \mu \mathrm{F} / \mathrm{cm}^{2}$ & 97.389 & 37.317 & 3.364 & 3.076 \\
\hline $\mathrm{W}-\mathrm{R}$ & - & - & - & 298380.000 \\
\hline $\mathrm{W}-\mathrm{T}$ & - & - & - & 5.786 \\
\hline $\mathrm{W}-\mathrm{P}$ & - & - & - & 0.524 \\
\hline
\end{tabular}

